\title{
Hydrodynamic Modelling of Marine Renewable Energy Devices: A State of the Art Review
}

A H Day ${ }^{\mathrm{a}}$, A. Babarit ${ }^{\mathrm{b}}$, A. Fontaine ${ }^{\mathrm{c}}, \mathrm{Y}-\mathrm{P} . \mathrm{He}^{\mathrm{d}}$, M. Kraskowski ${ }^{\mathrm{e}}$, M. Murai ${ }^{\mathrm{f}}$, I. Penesis $^{\mathrm{g}}$, F. Salvatore ${ }^{\text {h }}$ H-K. Shin ${ }^{\mathrm{i}}$

a) University of Strathclyde, Glasgow, Scotland.

E-mail: sandy.day@strath.ac.uk (Corresponding Author)

b) École Centrale de Nantes - CNRS, Nantes, France

c) Pennsylvania State University, State College, PA, USA

d) Shanghai Jiao-Tong University, Shanghai, China

e) Centrum Techniki Okrętowej (CTO), Gdańsk, Poland

f) Yokohama National University, Yokohama, Japan

g) Australian Maritime College, Launceston, Australia

h) Istituto Nazionale per Studi ed Esperienze di Architettura Navale (CNR-INSEAN) Rome, Italy

i) University of Ulsan, Ulsan, Korea 


\begin{abstract}
This paper reviews key issues in the physical and numerical modelling of marine renewable energy systems, including wave energy devices, current turbines, and offshore wind turbines. The paper starts with an overview of the types of devices considered, and introduces some key studies in marine renewable energy modelling research. The development of new International Towing Tank Conference (ITTC) guidelines for model testing these devices is placed in the context of guidelines developed or under development by other international bodies as well as via research projects. Some particular challenges are introduced in the experimental and numerical modelling and testing of these devices, including the simulation of Power-Take-Off systems (PTOs) for physical models of all devices, approaches for numerical modelling of devices, and the correct modelling of wind load on offshore wind turbines. Finally, issues related to the uncertainty in performance prediction from model test results are discussed.
\end{abstract}

The paper is based on the report of the International Towing Tank Conference specialist committee on Hydrodynamic Modelling of Marine Renewable Energy Devices to the $27^{\text {th }}$ ITTC held in Copenhagen, Denmark in 2014 (ITTC, 2014a). 


\section{LIST OF ACRONYMS}

Acronyms which are used throughout the text are listed below

$\begin{array}{ll}\text { BIEM } & \text { Boundary Integral Equation Method } \\ \text { BEM } & \text { Blade Element Method } \\ \text { BEMT } & \text { Blade Element Momentum Theory } \\ \text { CFD } & \text { Computational Fluid Dynamics } \\ \text { EMEC } & \text { European Marine Energy Centre } \\ \text { FOWT } & \text { Floating Offshore Wind Turbine } \\ \text { HACT } & \text { Horizontal Axis Current Turbine } \\ \text { IEA } & \text { International Energy Agency } \\ \text { ITTC } & \text { International Towing Tank Conference } \\ \text { MRE } & \text { Marine Renewable Energy } \\ \text { TLP } & \text { Tension Leg Platform } \\ \text { TRL } & \text { Technology Readiness Level } \\ \text { TSR } & \text { Tip Speed Ratio } \\ \text { OC3 } & \text { Offshore Code Comparison Collaboration } \\ \text { OC4 } & \text { Offshore Code Comparison Collaboration, Continuation } \\ \text { OC5 } & \text { Offshore Code Comparison Collaboration, Continuation, with Correlation } \\ \text { OWC } & \text { Oscillating Water Column } \\ \text { OWT } & \text { Offshore Wind Turbine } \\ \text { PIV } & \text { Particle Imaging Velocimetry } \\ \text { PTO } & \text { Power Take Off } \\ \text { RANSE } & \text { Reynolds-Averaged Navier-Stokes Equation } \\ \text { RMS } & \text { Root-Mean-Square } \\ \text { RPM } & \text { Revolutions Per Minute } \\ \text { VACT } & \text { Vertical Axis Current Turbine } \\ \text { WEC } & \text { Wave Energy Converter }\end{array}$

\section{OVERVIEW}

\subsection{Technology Readiness Level}

The stages of development of marine renewable energy devices are commonly described in the industry in terms of Technology Readiness Levels (TRLs). These provide a consistent process enabling identification of the stage of development of a device and identification of suitable test procedures for evaluating device performance at a defined stage of development. This information can then be used to provide an unbiased assessment of a device for investment/development purposes independent of device type or scale. 
In the case of the renewable energy industry, the following stages of Technology Readiness Levels (TRLs) are commonly considered (e.g. Mankins (2009)). TRL 1-3 correspond to research stages up to and including proof of concept, TRL 4-5 correspond to component, sub-system and system validation in laboratories and/or simulated operational environments and TRL 6-9 correspond to prototype demonstration in operational environment through to system proving via successful deployment.

\subsection{Wave Energy Converters}

Device Types. Wave Energy Converters (WECs) are devices designed to convert wave energy into another useful form of energy. In most cases the target is electricity generation but other uses have been proposed, such as fresh water production by desalination.

Wave energy is characterised by a wide diversity of concepts and technologies. At present, more than one hundred projects are in development around the world. More than one thousand patents have been filed, the earliest being as old as 1799 by Girard and Sons. Excellent reviews of wave energy technologies can be found in Falcao (2009) and Falnes (2007). The majority of devices use one of three following working principles:

Overtopping Devices: In these devices, waves run over a ramp in order to fill a reservoir in which the mean water level is higher than the mean sea water level. Potential energy in the reservoir is then converted into electricity using conventional low head turbines. Figure 1 shows two examples of prototypes.

Oscillating Water Columns: Oscillating Water Columns (OWCs) have a partly submerged structure with an inner chamber with an internal free surface. Pressure variations in the incident waves excite the internal free surface to oscillate via a submerged opening in the chamber. The free surface oscillation forces the air above to flow through an air turbine that drives a generator. Examples of well-known prototypes are shown in figure 2.

Oscillating Bodies: In these devices, incident waves make one or several bodies oscillate. Relative motions between the bodies and the sea bottom or between the bodies themselves are used 
to drive a Power Take Off system (PTO), often based on hydraulic components. The working principles and examples of well-known prototypes are shown in figure 3.

Other Devices: Some devices may use other working principles. Wave turbines have been proposed for instance, in which wave induced flow velocity is used with lifting surfaces in order to drive rotary generators (Siegel et al., 2013). Partly or even fully flexible devices have also been considered (Bellamy et al., 1986, Farley et al., 2011).

WEC Classification. WECs may be classified in a number of ways. One approach often used is to classify by the working principle; Figure 4, taken from Falcao (2009), shows a well-known example.

WECs may also be classified using the location of installation. Some wave energy converters are designed to be installed at the shoreline, some in near-shore shallow-water regions while other can be installed in deep water offshore.

A final approach to classification of WECs uses considerations of size. Devices of small dimensions with respect to wavelength are called “point absorbers”. Examples are Carnegie's Ceto device or the Aquamarine's Oyster. Large devices with the longest dimension parallel to the wave crests are called "terminators", whereas devices with the longest dimension parallel to the wave propagation direction are called "attenuators". The Wavedragon is an example of a terminator and the Pelamis is an example of an attenuator.

Landmark Studies. Modern studies in wave energy can be traced back to the 1974 paper by Salter and the 1975 paper by Budal and Falnes in Nature, and the 1976 paper by Evans in Journal of Fluid Mechanics. This pioneering work initiated a considerable amount of research on wave energy until the mid-1980s, when funding stopped partly because of the decline in the oil price. References to many interesting studies which were conducted at that time can be found in the review paper by Falnes (2007) and in McCormick (1981), Berge (1982) and Evans \& Falcao (1985).

Interest in wave energy started again in the mid-1990s, due to increasing awareness of issues associated with climate change and thus the need for renewable energy. From 1998 to 2002, an experimental program investigated several wave energy concepts in Denmark (Meyer et al., 2002). A techno-economic study of the deployment of WEC arrays based on early 2000s technologies was 
carried out in the US in 2004 (Previsic, 2004). Books were published by Falnes (2002) and Cruz (2008). In addition to device-specific R\&D, scientific research has been carried out on assessment of wave energy resource (Kerbiriou et al., 2007, Folley \& Whittaker, 2009, Saulnier et al., 2011), on device control for maximising power capture (Hals et al., 2002, Babarit \& Clément, 2006, Babarit et al., 2009, Crétel, 2011, Clément \& Babarit, 2012, Fusco \& Ringwood, 2012), on device performance (Babarit et al., 2012) and on array interactions (Folley et al., 2012, Babarit, 2013).

Many device concepts have been proposed and developed to moderate TRLs; however, while a few have been demonstrated at full scale at sea for several years, there are still no commercial wave farms in operation due to the high cost of wave energy in comparison with other renewable energy sources. Much work is still required to achieve economically-competitive energy from wave power.

\subsection{Current Energy}

Device types. Marine current devices are designed to convert the kinetic energy of flowing water into electrical energy by means of mechanical parts that undergo rotational or oscillatory motions in reaction to current-induced hydrodynamic forces. Electric generators typically convert motions into electric power.

Devices can be classified as turbine systems when moving parts consist of rotor blades and nonturbine systems. Marine current turbines are further classified according to the orientation of the turbine axis with respect to the dominant direction of the current. Turbines operating with the axis aligned with the current are referred to as horizontal axis turbines to distinguish from cross-flow turbines in which the axis is orthogonal to the current direction. Vertical-axis turbines represent a particular case of cross-flow turbines. Non-turbine devices present a variety of configurations. The most common cases utilise moving parts consisting of oscillating lifting surfaces such as foils, sails or kites. Other systems are based on the VIV (Vortex-Induced Vibration) cylinder concept.

In some cases, marine current devices are also divided between systems designed for unidirectional currents (ocean current devices) and those specific for bi-directional tidal currents (tidal devices). The present discussion is limited to devices converting the kinetic energy associated with flowing water masses (hydrokinetic devices). A further type of tidal device is designed to 
exploit potential energy from tidal range (rise and fall); these devices, sometimes described as tidal barrages, are considered as hydropower systems and are not addressed here.

Energy conversion mechanisms are generally fully submerged and may be positioned at various depths from the free surface. Existing technologies include bottom-fixed devices as well as floating and mid-water devices in which one or more turbines or equivalent mechanisms are fitted to surface platforms or submerged moored structures. Figure 5 shows some examples of turbine and nonturbine concepts. A review of marine current device technologies can be found in Khan et al. (2009).

Operational Aspects. In spite of the large number of concepts proposed over the last decades and the extensive analysis and design studies carried out by numerical modelling, laboratory tests and field trials of large-scale prototypes, marine current device technology is still at an early stage of maturity.

Recent state-of-art surveys by international organizations (e.g. Ocean Energy Systems Annual Report 2012, Brito e Melo \& Huckerby (2012)) highlight that turbine systems are considered as the most promising technology, in parallel with developments in wind energy devices. In particular, Horizontal Axis Current Turbines (HACTs) and Vertical Axis Current Turbines (VACTs) are to date the most widely-adopted solutions.

Each of these two layouts presents advantages and disadvantages. In terms of power efficiency, that is the amount of power that is produced for given momentum of the water mass processed by the device, HACTs have in general higher performance than VACTs. Conversely, HACT power capturing capability is very sensitive to the alignment of turbine axis and current direction, whereas VACTs are insensitive to the direction of the onset flow in a plane normal to the turbine axis. For this reason, the latter are frequently preferred in case of bidirectional tidal currents, whereas the operation of HACTs in tidal current sites implies that suitable blade/turbine orientation solutions are implemented. A simple solution for HACTs is to adopt blades with bidirectional profiles that do not require to be oriented according to tide direction, at a price of reduced hydrodynamic efficiency.

In the case of deployment in shallow water sites, bottom-fixed installations of HACTs are preferred, but many examples of floating turbines exist. VACTs are typically appended to floating 
platforms with the advantage that the generation set and power control systems can be placed on the platform above the water surface yielding inherent advantages in terms of inspection and maintenance operations. A disadvantage of floating devices is vulnerability in case of extreme weather conditions (e.g. hurricanes) which pose a lesser threat to submerged installations.

Turbines operating inside a converging/diverging nozzle or duct are sometimes introduced as means to increase the power output of similarly sized rotor devices deployed in relatively lowspeed/low-energy currents. The geometry of ducts can be designed to accelerate the water flow incoming to the turbine. Ducting solutions exist for HACTs, VACTs, and other cross-flow devices, as shown in Figure 6; Khan et al. (2009) gives a literature review on the subject.

In general, the addition of a duct or nozzle increases device drag thus increasing support structure complexity. In an open environment where the size of the device is small relative to the available open area of flow in the deployment site (low blockage of the device), the increased drag of the device will effectively deflect more incoming flow around the device rather than through it. Thus the overall power capacity of the device may be comparable to or worse than a similarly sized HACT with a rotor diameter equal to the duct diameter, (van Bussel et al. (2007)). A duct or shroud may be beneficial in more confined deployment sites or sites with debris as the duct may offer a level of protection to the rotor. Some device designs use a duct or shroud to house a rim drive generator unit. Figure 5(g) shows a commercial device of this type.

Biofouling is an issue with potentially great significance to the long term operational performance and the cost of maintenance for current turbine devices. Relatively few studies have been made addressing specific biofouling issues for current turbines; however the work of the $26^{\text {th }}$ ITTC Specialist Committee on Surface Treatment (ITTC, 2011) provides a through summary of relevant work on ship propellers, much of which may be applied directly to HACT devices.

State of Art technology \& ongoing projects. Technology development plans are advanced in many regions characterised by intense ocean and tidal current resources. This includes primarily the so-called Atlantic Arc in Europe, Canada in North America, Indonesia, India, China, Korea and Japan in Asia and Australia. While new concepts are often originally proposed by small companies and research teams, marine current technologies have captured the interest of leading companies with core business in the area of energy and marine propulsion systems. 
Large-scale exploitation of marine current energy is still in the future; however the situation is expected to evolve rapidly during the next decade considering the number of projects for array deployment that have obtained necessary consent and funding in the last few years. Projects for realization of horizontal-axis tidal turbine arrays with capacity of $10 \mathrm{MW}$ and more are planned in U.K., France, Canada, Korea, Australia, and India.

One of the projects most advanced in development is the MCT SeaGen shown in Figure 7 a 1.2MW horizontal axis tidal device deployed and operational since 2008 at Strangford Lough, Northern Ireland (Fraenkel (2010)). The system consists of twin power trains mounted on a crossbeam supported by a bottom fixed tower. The cross beam can be raised above the free surface for maintenance. Each turbine has a diameter of $16 \mathrm{~m}$ and two blades that can be pitched through 180 degrees to operate in bi-directional flows with current speed of $2.5 \mathrm{~m} / \mathrm{s}$. The company has plans to deploy a 10MW turbine array in Wales and an 8MW tidal farm in Scotland. Other examples of smaller horizontal-axis turbines are operating and grid-connected along the UK and Canadian coasts.

Many ongoing projects show results of open sea field tests for device assessment in view of precommercial deployment. In particular, several HACT prototypes with rated power up to 1 MW have been tested at the European Marine Energy Centre (EMEC) in the Orkney Islands (U.K.) and in other field tests worldwide. Tests are primarily aimed at confirming performance estimates from computational models and from small scale laboratory tests at large scale and in real environmental conditions. Trials are also aimed at verifying operability in extreme conditions, grid connection, deployment and maintenance aspects and to analyse life-cycle performance and reliability over testing periods ranging from several weeks to many months.

An example of these projects is the HACT tested in 2011 for three months off the coasts of South Korea near the island of Jindo, shown in Figure 8 (a). This is a $5.3 \mathrm{~m}$ diameter turbine with three symmetrically shaped blades for operation in bi-directional tidal currents, rated power of 110 $\mathrm{kW}$ with a current speed of $2.9 \mathrm{~m} / \mathrm{s}$. This represents a $1: 3$ scaled pilot installation. The full scale prototype, with rated capacity of $1 \mathrm{MW}$ at a current speed of $2.9 \mathrm{~m} / \mathrm{s}$, is being tested at EMEC. 
Similarly, the HACT turbine in Figure 8 (b) has been tested, firstly as a 1:3 scaled prototype in open sea in Norway for more than five years and subsequently by testing a full-scale $1 \mathrm{MW}$ unit at EMEC. A $10 \mathrm{MW}$ power array utilising these turbines is intended to be deployed in Scotland in 2015 as one of the world's first commercial-scale tidal arrays. A ducted, rim-driven horizontal-axis turbine, Figure 8 (c), has been tested at EMEC in 2008 and two $16 \mathrm{~m}$ diameter, $2 \mathrm{MW}$ power capacity units are being deployed at the Fundy Ocean Research Centre for Energy (FORCE), Fundy Bay, Canada.

The first grid-connected VACT device is the small Kobold straight-blade Darrieus type turbine deployed since 2002 in Messina Strait in Italy. A three-bladed, $5 \mathrm{~m}$ diameter prototype with rated capacity of 120-150 kW is being deployed off the coasts of Lomboc Island, Indonesia. Other VACT projects are ongoing in Korea and in China, where a research team from Harbin Engineering University has developed a $300 \mathrm{~kW}$ device consisting of two $150 \mathrm{~kW}$ turbines fixed to a catamarantype platform.

Landmark studies. This section describes representative experimental studies conducted with the main objective of investigating specific aspects of marine current energy capturing mechanisms and device operation and to provide datasets for the validation of computational models.

Results of a detailed set of model tests of a horizontal axis turbine conducted in a towing tank and in a cavitation tunnel are presented by Bahaj et al. (2007). Power and thrust measurements of a three-bladed turbine under various hydrodynamic flow conditions are reported. In particular, the effect of yaw angle, rotor immersion, and the interference between twin rotors were studied. Cavitation inception studies are also reported.

Extensive studies of horizontal axis turbines have been carried out at the flume/wave tank by IFREMER (France). Wave-current interaction studies (Gaurier et al., 2013) have shown that freesurface waves induce additional cyclic loading on turbine blades and fatigue conditions are dominated by wave-induced loads. Turbine wake flow studies by Laser-Doppler velocity measurements have been presented in Maganga et al. (2010) and the analysis of the impact of onset flow turbulence on turbine performance and shed wakes is discussed in Mycek et al. (2014). The interaction between two turbines has been addressed in Mycek et al. (2013). 
Milne et al. (2013) studied the impact of unsteady inflow on blade loading on a three-bladed rotor by towing the test-rig on an oscillating sub-carriage mounted on the main carriage of a towing tank, investigating single and multi-frequency oscillations. Results showed that flow separation leads to significant increases in loading, but for attached flow the effects of unsteadiness are shown to be rather smaller.

Fontaine et al. (2013) performed a detailed verification and validation experiment on a $0.575 \mathrm{~m}$ diameter model of a 3-bladed HACT designed with improved cavitation performance, reduced sensitivity to fouling and reduced blade noise. This test generated a detailed data set for computational model development that included device powering, shaft steady and unsteady loads, blade strain, measured device acoustics, blade cavitation performance, tower unsteady pressure, nacelle vibration, and detailed flow mapping of the inflow and wake structure up to one rotor diameter downstream with phase locked multi-component Laser Doppler Velocimetry (LDV) and Stereo PIV. The tests were conducted over a range of blade chord Reynolds numbers from $3 \times 10^{5}$ to nearly $1 \times 10^{6}$ with Tip-Speed Ratios 2-7 and under cavitating and non-cavitating conditions. The data base is one of the first produced providing device structural response, blade strain and drive shaft steady and unsteady load, as a function of inflow conditions and blade tower interaction.

Wang et al. (2007) studied the cavitation, noise and slipstream wash characteristics of a horizontal-axis current turbine in a cavitation tunnel order to assess the environmental impact. A $400 \mathrm{~mm}$ diameter model was used with Reynolds number between $2-3 \times 10^{5}$. Results showed that the turbine can experience strong unstable sheet and cloud cavitation as well as strong tip vortex cavitation at a shallow depth of shaft submergence which can result from a wave trough passing over the turbine. The measured noise level of the turbine is increased due to the presence of cavitation, whilst the slipstream wash may have an impact on scour on the seabed if a turbine is positioned too close to it.

Recently, a three-bladed turbine model with $0.7 \mathrm{~m}$ diameter has been selected as the reference geometry for a Round-Robin test in the framework of the R\&D Project MaRINET co-funded by the European Union. At the time of writing, tests have been conducted by IFREMER (France), the University of Strathclyde (Scotland) and CNR-INSEAN (Italy). The aim of this program is to compare turbine performance measurements conducted in facilities of different type (towing tanks, 
flume tanks and circulating water channels) and investigate the impact of testing energy capturing devices towed in calm water or kept fixed in an onset flow with non-negligible turbulence levels. Plans to repeat part of measurements using models of identical geometry and different scales have been made by CNR-INSEAN. Similar comparative studies on vertical-axis devices are not reported to date.

An example of experimental study aimed at analysing the performance of horizontal-axis turbines in an array is proposed by Myers and Bahaj (2012). The flow field around a 2-row array, device/device interaction as well as the structure of shed wakes downstream the rows is investigated by simulating single turbines as porous actuator disks with $100 \mathrm{~mm}$ diameter (Figure 9). AcousticDoppler Velocimetry (ADV) was used to measure velocity fields. Results demonstrate that unit positioning combinations exist that allow an increase of the overall power output capability of the array.

A key benefit of the collection of experimental data describing turbine performance under different operating conditions is to provide datasets for the validation of computational models. Although these tests provide a valuable data set, in many cases, the small scale of model devices result in flow conditions in which transitional effects and turbulence development must be carefully evaluated to ensure that test results are not biased by low Reynolds number effects.

\subsection{Offshore Wind Energy}

An offshore wind turbine system generates electricity from the energy of wind over the sea. Wind farms consist of arrays of offshore wind turbines. Offshore wind turbine systems may be divided into bottom-mounted and floating systems. Bottom-mounted systems typically utilise foundation technology of monopiles, tripods, jackets and gravity bases. Floating Offshore Wind Turbines (FOWTs) utilise floating support structures in many cases utilising technology originally developed for the offshore oil and gas industries. In the wind-turbine literature these are often categorised as ballast-stabilised (e.g. Spars), Mooring-stabilised (e.g. TLPs) and buoyancystabilised (e.g. barges and semi-submersibles). While bottom-mounted systems are currently operating commercially in several European countries, FOWTs are still in a process of evolution with several technology demonstration projects under way around the world. Some hybrid concepts are under development, attempting to exploit potential for synergy between wind and current or 
wave energy systems. As of 2013 the two largest offshore wind farms are located in UK waters: the 630 MW London Array (Figure 11) is the largest offshore wind farm in the world, with the 504 MW Greater Gabbard wind farm the second largest. All turbines are of the bottom-mounted monopile type.

A number of FOWT projects are in the demonstration stage of full-scale or large-scale trials at sea. The first demonstration experiment of a FOWT was Blue H's tension leg platform with a small wind turbine installed in Italian waters in 2008. A number of larger scale (c.2MW) technology demonstrators have followed. One is Hywind [4] the first large-scale spar type FOWT installed by Statoil ASA off the south-west coast of Norway in 2009. WindFloat [5] is a semisubmersible type FOWT installed by Principle Power Inc. in 2011 off the coast of Aguçadoura, Portugal.

The Japanese government has recently started three technology demonstration projects in offshore wind. The first is a 2.0 MW spar-type offshore wind turbine located off Goto Island near Kyushu. The second is the 16.0 MW floating offshore wind farm technology demonstration Fukushima Project which consists of 4 floating devices: a three-column triangular semisubmersible (2MW), an advanced Spar (7MW) and an V-Shape semi-submersible (7MW), supported by the first floating sub-station in the world. The first electricity was generated in 2013; the 7MW FOWTs will be installed in 2014 and 2015. Finally the first demonstrator of a large-scale vertical-axis type FOWT is the SKWID hybrid wind-current device which is planned to be installed in Saga, Japan by MODEC.

There is rapid increase in capability of simulation codes for FOWTs, such as those developed by NREL (USA), Risø (Denmark), IFPEN (France), and MARINTEK (Norway). In recent years, development of simulation codes has focussed on addressing aero-hydro-servo-elastic coupling of FOWTs. One example is the coupling of WAMIT developed by MIT and FAST developed by NREL to predict dynamic characteristics of FOWTs and estimate their parameters' effects on performance.

Some of the well-known prediction tools for wind turbines have been benchmarked through the International Energy Agency (IEA) Wind Project Annex 23 Offshore Code Comparison Collaboration (OC3) reported by Jonkman and Musial (2010) which included analysis of monopile and tripod bottom-mounted wind turbines and a spar buoy floating turbine. Benchmarking 
developments are continuing with the ongoing project Annex 30 Offshore Code Comparison Collaboration Continuation (OC4), which addresses analysis of jacket-mounted OWTs (Popko et. al (2012)) and semi-submersible FOWTs (Robertson et. al (2013)).

The increasing size of full-scale wind turbines requires that experiments adopt relatively small scale models. Devices currently being deployed employ turbines up to $170 \mathrm{~m}$ in diameter, and sizes may continue to increase as offshore installations become more economically attractive both in land and offshore. Consequently it is difficult to keep the physical similarities of not only the scale of the model but also the external wind load conditions. Most of the experiments of 2-7MW FOWTs in a conventional ocean basin or test tank now use 1/50-1/200 scale models. Some particular challenges of these tests are addressed in Section 5.

\section{DEVELOPMENT OF BEST PRACTICE GUIDELINES FOR MODEL TESTING OF MARINE RENEWABLE ENERGY DEVICES}

One of the key tasks of the ITTC Specialist Committee on Hydrodynamic Modelling of Marine Renewable Energy Devices for the 27th ITTC was to propose revisions to the existing best practice guideline on physical model testing of wave energy devices and to develop two new best practice guidelines addressing model testing of current turbines and offshore wind turbines respectively.

This task should be seen in the context of the proliferation of other guidelines addressing development of Marine Renewable Energy (MRE) devices, and which consider issues related to model testing either directly or indirectly. These other guidelines have been developed by a diverse set of organisations, including international standards bodies, intergovernmental organizations, and national and international research projects. Some examples of guidance related to tank-testing of MRE devices either in existence or known to be under development by international bodies are given in Table 1 whilst examples of guidance developed by research organisations and/or projects are listed in Table 2.

Much of this guidance has been generated by groups including few or no representatives from ITTC organisations. The emphasis of much of this work is to advise device developers, sponsors/investors and/or regulators on the processes required in order to assess device performance at various stages of device design and development, including hydrodynamic model testing. 
However, much of the guidance given is rather general and does not address the specific nature of many critical challenges of tank testing MRE devices. In contrast the guidelines proposed by the ITTC committee aim at providing guidance to research organisations conducting tests on MRE devices on specific issues related to the execution of the tests themselves.

The guidelines proposed (ITTC 7.5-02-07-03.7 (ITTC, (2014b)), ITTC 7.5-02-07-03.8 (ITTC (2014c)) and ITTC 7.5-02-07-03.9 (ITTC (2014d))) were adopted by the 27th ITTC in Copenhagen in 2014 and published on the ITTC web site.

\section{PHYSICAL MODELLING OF POWER TAKE-OFF SYSTEMS}

\subsection{Introduction}

One of the key differences between the behaviour of a marine renewable energy device and other fixed or floating structures subject to fluid action is the presence of a Power Take Off (PTO) system specifically designed to extract energy from the interaction between the device and the fluid flow. The device performance, in terms of power capture as well as other aspects of the device response such as motions and/or hydrodynamic loads, thus depends upon the behaviour of the PTO system. Hence appropriate simulation of the power take-off is essential during small-scale model tests to determine the performance of the system.

It should be noted that the term PTO refers specifically to the system which converts energy from one form (typically kinetic or potential) into another form (typically electrical). The term Power Conversion Chain (PCC) is sometimes used to describe the entire system with which the energy is converted and transmitted to shore - hence this could include components such as PTO, power conditioning systems, and cabling.

\subsection{Wave Energy Devices}

The PTO in a wave energy device typically extracts energy from relative motion between different components of the device, or directly or indirectly from relative motion between the device and the water. The corollary to this is that the amplitude of the motion of the structure can be 
strongly coupled to the amount of energy extracted, and in turn the amount of energy extracted can be strongly coupled to the damping employed. Thus the simulation of the device requires that the model-scale PTO behaves in a manner which correctly represents the behaviour of the full-scale system over the range of oscillation amplitude and frequency. In addition it is important that the model-scale PTO allows the damping to be repeatably varied in order to allow systematic investigation of the power extraction.

A key limitation in the implementation of model-scale PTO simulators is the model size and scale. Scale is important since some of the parasitic loads, particularly friction will not scale according to Froude scaling used to scale the hydrodynamic loads, whilst size is important since it may be challenging to build a simulated PTO to meet geometry and mass constraints in even relatively large scale models of small devices.

At early stages of testing (e.g. TRL 1-3) it is likely that the detailed design of the full-scale PTO is not complete, and hence the model test will typically utilise a simplified or idealised damper. Whilst it may not be necessary at this stage of testing to generate a numerically-quantified level of damping, a minimum requirement is that the damping can be controlled in a repeatable manner; this can be problematic with friction-based systems which are sensitive to environmental factors such as temperature and moisture.

It is important to characterise damping systems prior to the tank tests in order to gain an understanding of the behaviour of the system so as to determine the extent to which the system behaves in the idealised manner intended. With passive systems this may be achieved by applying a known motion to the PTO using an appropriate test rig (e.g. Sheng et al. (2013)), ideally over the full range of frequencies and amplitudes expected in the tests.

At this stage the damper may be passive or active. Passive dampers typically employ a variety of mechanisms: on oscillating water columns, an orifice plate or a porous medium is often used to damp the airflow in and out of the air chamber. Orifice plates behave in an approximately quadratic manner, with some hysteresis, whilst porous media behave more like a linear damper (Sheng et al. (2013)); however some studies have shown that the resulting differences in power capture are relatively small (Forestier et al. (2007)). Tests should take correct account of air compressibility by appropriate scaling of the air chamber (Weber (2007)). 
Instantaneous power capture in an OWC is normally found from the product of air pressure and flow rate. The pressure drop across the damper is normally measured directly using a differential pressure transducer. Direct measurement of the air flow through the damper is challenging; flow rate is normally calculated from the rate of change of the air volume in the OWC which in turn is inferred from measurements of water surface elevation inside the OWC. These measurements typically employ conventional capacitive or resistive wave probes. Where the duct dimension is large enough that significant sloshing may occur, it may be necessary to deploy several probes in order to capture the slope of the water surface in the duct and thus find the air flow rate.

A possible alternative is to use an optical system to measure the response of floats inside the OWC; in this case it is important to ensure that the natural frequencies of the float in the duct are well above the wave frequencies of interest in the test.

On overtopping devices, the overtopping power is proportional to the height of the crest of the artificial "beach" above mean water level and the mean overtopping flow rate. It is therefore necessary to measure the flow rate of the water overtopping the crest. This may be achieved by direct measurement of water flow or by collecting the overtopped water and measuring the total volume over a period of time (e.g. Parmeggiani et al. (2013)).

On oscillating body devices, small-scale hydraulic or pneumatic systems or friction-based systems may be used on oscillating body devices. Typically the power will be obtained from the product of force and relative velocity between two components. Force is normally measured with a conventional tension / compression or torque load cell. For devices which generate power from rotational motion, the angular velocity will normally be found from the time derivative of the output from a potentiometer or encoder. Where devices generate linear motion, a device such as an LVDT may be used to measure the instantaneous position. In both cases, and especially where the PTO motion is underwater it may be preferred to use an optical motion capture system to derive the relative motion.

As an alternative to dissipating energy through a damper, the energy may be converted into another form, such as potential energy stored by lifting a weight or by pumping water. 
For tests at higher TRLs, active dampers using closed-loop control systems are normally employed. These may still be used with relatively simple control models to represent idealised PTOs such as linear or quadratic dampers (e.g. Ersdal \& Moe (2013)), or may incorporate more complex control strategies.

The more complex strategies typically employ phase control with highly-tuned devices, such as point absorbers, in order to broaden the frequency range at which high response occurs. In latching control (e.g. Bjarte-Larsson \& Falnes (2007), Durand et al. (2007)) the relative motion is temporarily fixed, normally at an instant of zero relative velocity, and then released once the relative force exceeds a prescribed value. In reactive control, energy is both extracted and injected into the system at different points in the cycle, as described by Hansen and Kramer (2011)) for the Wavestar prototype device. Both strategies can increase the root-mean-square (RMS) power output compared to that obtained with a simple damping strategy; however the increase in RMS power often comes with a price of increased peak loads on the system. Any of these strategies may be implemented through a variety of hardware systems including digital drives (e.g. Ersdal \& Moe (2013), embedded controllers (e.g. Signorelli et al. (2011) for a PTO test rig) or Programmable Logic Controllers (PLCs) (e.g. Banks et al. (2013)).

A key requirement of the mechanical design of the model and the simulated PTO is to minimise friction in the system, both static ("stiction") and dynamic, since the friction will not scale correctly with Froude scaling, and will potentially distort the relationship between force and velocity being simulated in the PTO. Careful design, including the use of specialised components such as air bearings (e.g. Lamont-Kane et al. (2013)), can substantially reduce the impact of friction on the system response. Where possible it may be beneficial to locate the load cell so that the measured load includes loads due to mechanical friction in the system, so that the power dissipated through friction is included in the total power measured.

\subsection{Current Turbine Devices}

In general, PTO modelling in current/tidal based renewable energy devices is generally less demanding than for WECs. Current devices are typically designed to operate over a specific range of conditions, typically RPM or oscillation frequency, for optimal power generation. Maintenance 
of optimal conditions is usually achieved by loading the device to hold RPM or oscillation to a desired range. An unloaded device would typically operate under freewheeling conditions often undesirable at full scale and producing minimum shaft power. The PTO system, comprised of drive train, power generation and power electronics, is the sub-system that provides the necessary device loading. Proper small-scale device testing must include some form of PTO modeling.

The important parameters of interest relative to PTO function in a small-scale model test of a rotating device are shaft RPM and torque at the rotor to shaft attachment. The small-scale PTO must be designed to absorb the delivered power by the shaft under controlled conditions to minimize shaft torque and rpm drift during testing. In tests of model current devices, the PTO can be represented by direct electrical power generation, by mechanical / hydraulic / magnetic loading or by using a speed or torque control drive to control rotor RPM.

Generators, either permanent magnet or inductance, can be used in small scale model testing using direct-drive or gear-box coupling. While full-scale devices often have the power generator installed in the nacelle, space limitations in small-scale model testing may require a revised configuration where the generator is installed in a downstream dynamometer or outside the facility. These adaptations often involve additional components like seals, bearings and gearbox configurations.

It is very important to quantify the small scale PTO characteristics and operation to properly understand device function. Key properties include system efficiency, resistance to movement which can impact turn on/off characteristics of the device and system tares. For small-scale tests, model dynamics and drive-train friction losses cannot normally be scaled appropriately; thus friction associated with bearings and seals must be carefully assessed in order to minimize the impact on the measured power.

Redundant instrumentation packages should be employed where possible in which shaft torque is measured at or near the rotor shaft attachment and at the shaft generator attachment to give an accurate assessment of system efficiency losses at small scale. This provides a more reliable data set to be used in scale-up performance prediction. 
Resistance loading is usually accomplished with a drag type device attached to the PTO drive shaft. This can be mechanical, hydraulic or magnetic in design. This type of system is designed to control the rotation or oscillation rate of the device and does not directly simulate a power generation system. Typically, the hydro-kinetic power generated by the device is converted into heat within the PTO model or motion of a fluid within a hydraulic / pneumatic system. Power generated is computed by the product of measured shaft torque and shaft rpm. Resistance loading type PTO devices must be carefully monitored during a test to minimize bias errors being introduced into the results due to thermal effects or component wear. In particular, the magnitude of resistance loading that can be generated by a drag-type device has to be carefully checked in order to avoid shaft RPM drifting during tests when the model current device generates more power than the drag-type device can dissipate.

As an alternative to the approaches described above, a speed-controlled motor may be used to drive the rotor at a prescribed rpm. In this case the power is typically derived from measurements of shaft torque and rotational speed. In this approach the tip-speed ratio for the test is controlled directly through the combination of specified rotational speed of the motor and the onset flow velocity (e.g. Gaurier et. al (2013). It is important to ensure that the motor and controller have adequate torque to maintain steady speed throughout the range of tip-speed ratios of interest. As an alternative to controlling speed, a similar approach may be utilized to control the torque. Similar control methodologies can be established for oscillating devices where oscillation frequency rather than rotation is controlled.

Careful consideration should be given to the turbine control strategy in unsteady flow. If the desire is to model accurately the behaviour of the full scale system including the generator, then the dynamic response of the generator to the unsteady loads should be modelled correctly. Conversely, if the intention of the tests is to characterise the hydrodynamics of the rotor in unsteady conditions then the more idealised solution of using a speed-controlled motor to drive the rotor may be preferable, so that effects related to angular acceleration and deceleration of the rotor are removed (e.g. Milne et. al. (2013). This approach can offer a further advantage in towing tank (as opposed to flume) tests since the rotor may be accelerated to the desired angular velocity prior to the towing carriage starting, eliminating the impact of transients related to rotor acceleration on the time available for measurement. 


\subsection{Offshore Wind Turbines}

It should be noted that the terminology used in offshore wind turbines is somewhat different from that used in wave and current devices; the gearbox, generator etc. is usually described as the drivetrain in a wind turbine. The requirements for drivetrain simulation in hydrodynamic tests of offshore wind turbines are generally rather less demanding than those for PTO simulation in wave and current devices. The goal of hydrodynamic tests of offshore wind turbines is typically to examine structure motions and/or loads and possibly turbine control strategies, rather than to characterise the power capture performance of the turbine. This typically requires appropriate aerodynamic and gyroscopic loading to be generated by the rotor, so that the coupling between the turbine and the support structure is correct, but it is generally not required to measure power output. Strategies for achieving the appropriate loading are discussed in Section 5 below.

\section{NUMERICAL MODELLING OF MARINE RENEWABLE ENERGY DEVICES}

\subsection{Numerical Modelling of Wave Energy Converters}

Mathematical and numerical models of a wave energy converter (WEC) including simulations of both the body hydrodynamics and the power take-off are usually called Wave-to-Wire models (Josset et al., 2007). At early stages of device development, numerical models can allow rapid estimates of the energy capture performance of a device (Pizer, 1992, Josset et al., 2007, Payne et al., 2008, Kurniawan et al., 2011, Babarit et al., 2012), and provide powerful tools to gain insight in the behaviour of novel device configurations (Renzi \& Dias, 2012, Alam, 2012, Farley et al., 2011, Lovas et al., 2010). The use of efficient numerical models allows extended parametric studies and optimization to be performed more rapidly than can be achieved experimentally (Malmo et al., 1985, Babarit et al., 2005, Folley et al., 2007, Vicente et al., 2009, Gomes et al., 2011, Oskamp \& Ozkan-Haller, 2012, Falcao et al., 2012). 
The hydrodynamics of WECs consisting of rigid bodies are essentially no different to those for other marine structures in terms of the modelling methodology. Hence the response of wave energy devices to the marine environment can be studied using numerical frameworks similar to those adopted for other marine structures. In particular, linear potential theory is commonly utilised to determine wave loads acting on the device.

Many studies have utilised this approach to investigate performance of a wide range of device types and configurations. A number of authors have used this approach to model OWC devices including Malmo \& Reitan (1985), Lovas et al., (2010), Gomes et al. (2011), Kurniawan et al., (2011), and Falcao (2012).

A wide range of oscillating body devices have been modelled using linear potential theory. Pizer (1992) modelled the original Salter Duck. Payne et al. (2008) and Oskamp \& Ozkan-Haller (2012) modelled floating buoy devices. Babarit et al., (2005), Josset et al., (2007), and Ruellan et al., (2010) modelled the SEAREV floating oscillating-body device, while Folley et al. (2007a), Folley et al., (2007b) and Renzi \& Dias, (2012) modelled a bottom-hinged flap device similar to Oyster. Farley et al., 2011 modelled the flexible Anaconda device, while Vicente et al., 2009 addressed arrays of point absorber devices. Babarit et al., (2012) developed a numerical benchmark of a range of devices.

A key difference between modelling of WECs and other marine structures is the need to take into account the Power Take Off (PTO) in the modelling work, due to the strong coupling between the behaviour of the PTO, including both the mechanical components and the control strategy, the dynamic response of the device, and the energy capture.

It is commonly assumed that the PTO behaves as a linear spring and damper system (see, for example, Pizer, 1992, Hals et al., 2002, Babarit et al., 2004, Babarit \& Clément, 2006, Folley et al., 2007, Folley et al., 2007, Babarit et al., 2009, Vicente et al., 2009, Cretel et al., 2010, Gomes et al., 2011, Oskamp \& Ozkan-Haller, 2012, Renzi \& Dias, 2012, Clément \& Babarit, 2012). The adoption of a linear model of the PTO in conjunction with linear potential theory for the device hydrodynamics allows calculations to be made in the frequency domain which in turn yields fast computations. This is particularly useful in characterising the device performance over a wide range 
of environmental conditions, which requires many long duration simulations to avoid statistical biases.

However, the assumption of a linear PTO may be inaccurate when the full-scale PTO is hydraulic. In this case, Coulomb damping (dry friction) may be used (Babarit et al., 2012). Full models of the hydraulic PTO systems can also be considered (Henderson et al., 2005, Josset et al., 2007, Falcao, 2007) which are useful for selection of hydraulic components, and study of the behaviour of the hydraulic components (Yang et al., 2010). Due to the non-linear nature of these models, the numerical simulations must be performed in the time domain, leading to a higher computational cost. In case of fully electrical PTOs, a linearised model is more appropriate than in the case of hydraulics. Refined models may also be used in case of direct-drive electrical PTOs for specific studies (Ruellan et al., 2010, Tedeschi et al., 2011).

Numerical models are widely used for studying the impact of different control strategies on power capture and/or structural loading for WECs (see section 3.2). Latching control has been studied by Greenhow et al. (1984), Babarit et al. (2004), and Babarit \& Clément (2006). Hals et al. (2002) examined reactive control strategies. Declutching control was studied by Babarit et al. (2009), while predictive control was addressed by Cretel et al. (2010). Clément \& Babarit (2012) investigated discrete control strategies; Tedeschi et al. (2011), investigated the impact of irregular waves on the power extraction when using different control techniques.

For marine structures, numerical modelling is often used to determine their dynamic responses to the marine environment and to perform structural analysis. In the wave energy context, numerical Wave-to-Wire models are also employed to assess the energy capture performance of the devices. This is typically characterised via the so-called power matrix, which expresses the mean absorbed power as a function of the peak period and significant height of the wave spectrum.

The influence of directional spreading does not have to be taken into account in case of omnidirectional devices, such as heaving buoys, or in case of near-shore devices thanks to refraction effects (Folley \& Whittaker, 2009). For directional devices, some studies suggest that the influence of directionality is limited provided that the device is able to self-align with the mean direction of wave propagation (Kerbiriou et al., 2007). 
Characterization of the full power matrix implies a large number of long duration simulations (typically 1 hour). Structural analysis usually relies on statistical approaches. Hence, the Wave-toWire numerical model must be faster than real time in order to obtain results in a reasonable amount of computational time. Thus, at present, it is still generally infeasible to use high-fidelity models such as CFD solvers for computation of the fluid-structure interaction in a practical design or analysis problem due to limitations of available computational resource ( $\mathrm{Yu} \& \mathrm{Li}, 2012)$. However, CFD may be used to investigate particular effects in case of selected events (Babarit et al., 2009), or as an alternative to tank testing for calibration of empirical corrections, such as the viscous damping coefficients in Morison equation (Bhinder et al., 2011).

Although linear potential flow theory is often the only practical option, its limitations must be acknowledged. WECs are often designed to have their natural frequencies within the wave spectrum. Thus, the motion response of the device may be large, which violates the assumption of small amplitude motion. Significant discrepancies in comparison with experiments may be observed (Durand et al., 2007). Some research groups are putting efforts in developing medium fidelity models to address this issue, while keeping the computational cost moderate (Gilloteaux et al., 2007, Guerber et al., 2012).

Some WECs are composed of many articulated bodies with many more degrees of freedom than the conventional 6 DOFs for conventional rigid body motions (Soulard \& Babarit, 2012, Babarit et al., 2013). Boundary Integral Equation Methods (BIEMs) must be adapted to deal with this feature, using approaches such as generalised modes. Dedicated solvers may be developed in particular cases (Renzi \& Dias, 2012). In case of overtopping devices, linear potential theory cannot be used and one may rely on empirical laws (Borgarino et al., 2007).

As for other marine energy devices, wave energy converters are expected to be deployed in arrays consisting of many devices. The behaviour and performance of devices can be different in the array from that found for the isolated device due to wave interactions (Budal, 1977, Evans, 1979, Falnes, 1980). The wave farm may also have a significant impact on the local wave climate, possibly affecting coastal processes. These effects are challenging to assess in experiments due to the large physical size of possible arrays and the finite extent of test facilities. Thus, most of the research work on these subjects has been conducted numerically. 
Potential-theory based models or wave propagation models may be used to address these issues. Their advantages and drawbacks have been have been recently reviewed in Folley et al., (2012), from which the summary table 1 has been extracted. It shows that, at present, there is no single best numerical technique for WEC arrays. For wave propagation models, the key issue lies in taking proper account of the disturbance generated by the WEC or array of WECs. In contrast, for potential-flow solvers, the challenges relate to the bathymetry and the computational time. It can also be noted that whilst some experimental studies of WEC arrays have been published recently (e.g. Lamont-Kane et. al. (2013), Stratigaki et al. (2014)), these mainly address arrays of idealised small point absorbers and experimental validation for device types other than point absorbers and at larger scales is still generally lacking

\subsection{Numerical Modelling of Current Turbines}

Theoretical and computational hydrodynamics modelling plays a key role in the development of marine current devices. Numerical methods are primarily used to achieve a preliminary validation of concepts. At this stage, energy capturing mechanisms are investigated and rough estimates of power output capability are obtained. Simplified system layouts and operating conditions are considered, e.g., an isolated rotor in uniform axial flow.

At a later stage of technology development, computational hydrodynamics modelling is used in combination with physical model testing to analyse details of the flow-field around the device. Parametric studies are performed to investigate response to different operating conditions and to optimise geometry details. A more detailed representation of system components is usually addressed in this phase, e.g., rotor hubs and supporting structures, and device clusters. In addition to hydrodynamic performance, numerical studies also provide data for the structural design of the overall system.

In general, computational modelling provides analysis and design tools that are complementary to testing physical models in laboratories and field sites. In particular, aspects that cannot be reproduced by physical tests can be investigated by numerical simulations. This includes, for instance, estimation of scale effects on results of laboratory tests carried out on small models in order to provide reference data for the design of full-scale prototypes to be deployed in open water. 
The analysis of multiple device operations in arrays and the impact of energy capture on the environment are other examples of applications of computational models.

With few exceptions, turbine and non-turbine systems have in common that power is generated by means of lifting surfaces subject to rotary or oscillatory motions. According to the device type, these surfaces consist in turbine blades, foils or sails. The prediction of hydrodynamic forces generated on these lifting surfaces can be obtained by computational models with different levels of approximation used to describe relevant fluid-dynamics mechanisms. Due to similarities of energy capturing mechanisms and of device layouts to some extent, computational methods for marine current devices are closely related to models used for wind turbine modelling.

A broad classification can be set distinguishing global performance methods and flow-field models. The former class identifies simple approaches that provide an estimate of device power output by momentum and energy balancing of the water mass flowing through the device. Momentum theory, and Blade Element Method (BEM) and their combination, Blade Element Momentum Theory (BEMT) belong to this class. Very fast predictions of global hydrodynamic performance can be obtained using basic representations of geometry and operating conditions. An example is given by Bahaj et al. (2007a), where numerical results by two BEMT models are compared with experimental data from Bahaj et al. (2007b). The capability of BEMT to determine reliable performance estimates at early stage of design of horizontal-axis turbines is demonstrated.

Inviscid-Flow Models. Flow-field models aim at describing details of the hydrodynamic interaction between the device and the incoming flow by the numerical solution of mass and momentum equations. Under the assumptions of inviscid, irrotational onset flows, Lifting Line, Lifting Surface, Vortex Lattice, and Boundary Integral Equations Methods are derived. These methods provide estimates of turbine hydrodynamic loads and power with greatly reduced computational effort. Viscosity effects are only approximately taken into account and hence particular care has to be devoted to analyse blades and foils operating at high angle of attack where viscosity-induced effects such as boundary layer flow separation and static/dynamic stall have an impact on blade loads.

Examples of current turbine performance by inviscid-flow models are given in Falcao de Campos (2007) and Baltazar and Falcao de Campos (2008), where a 3D Boundary Integral 
Equation method (BIEM) is used to predict rotor forces and power over a range of values of Tip Speed Ratio (TSR) and yaw angles between 0 and 15 degrees. Numerical results are compared to experimental data in Bahaj et al. (2007b). The same methodology is applied in Salvatore and Greco (2008) to evaluate unsteady blade forces on vertical-axis turbines. In both papers the importance of coupling BIEM with trailing wake modelling and viscous-flow corrections is stressed.

The problem of predicting the trailing vorticity pattern shed by VACT blades is addressed by Li and Calisal (2010a, 2010b, 2011) using a 3D potential-flow vortex method with viscosity-effect correction. The impact of the wake shed by one turbine blade on the following blades is analysed for different configurations and the best performing layouts are determined.

Viscous-flow correction models are used to improve turbine blade load predictions from inviscid-flow models that cannot describe blade stall and post-stall conditions when blades are at high angle of attack, a common condition in case of operation at small TSR. In particular, cyclic variations of blade angle of attack over a revolution may determine transient separations of blade boundary layer with strong load peaks that are not observed under attached flow conditions. This mechanism, known as dynamic stall, is described in Ferreira et al. (2009).

Urbina et al. (2013) combine a lifting line approach with a dynamic stall model derived by the Beddoes-Leishman model widely used for helicopter rotors and wind turbines. Numerical results compared to experimental data (e.g. Figure 14) show that dynamic stall modelling is fundamental to correctly describe VACT blade loads and power,

Viscous-Flow Models. Although inviscid-flow models describe many aspects of current device/flow interactions, viscous-flow models based on the numerical solution of the Navier-Stokes equations provide a more physically- consistent and comprehensive approach to accurately describe a full range of system layouts and operating conditions.

The most popular approach among viscous-flow solvers is the Reynolds-Averaged NavierStokes Equation (RANSE) method. This methodology allows estimation of the effects of flow vorticity and turbulence on hydrodynamic loads. Turbulence modelling is introduced to avoid the explicit solution of eddies in the flow. If more detailed descriptions of local flow perturbations and 
of blade/foil generated wakes are necessary, Detached Eddy Simulation (DES) or Large Eddy Simulation (LES) models are preferred to RANSE approaches.

Viscous-flow methods are typically referred to as Computational Fluid Dynamics (CFD) methods. The main drawback with CFD is that computational set-up and computing effort can be very demanding also for simple problems. Dealing with turbines and oscillating foils, a complication is to capturing the interaction between rotating parts (e.g. blades) and non-rotating parts (e.g., supporting structures, diffusers) which requires fixed/rotating grid interface techniques.

To limit the computational burden, CFD modelling of turbines is often addressed using simplified models in which the blades are not explicitly solved as solid boundaries of the fluid domain but their effect is indirectly taken into account via suitable forcing terms in the momentum equations. Furthermore, the analysis of vertical-axis turbines is usually performed under the assumption of infinite-length blades, to reduce the problem to a 2D schematization.

Recent literature provides an amount of CFD studies for all kinds of current devices. As an example, the computational prediction of a horizontal-axis turbine by using the commercial RANSE solver ANSYS CFX is presented by Jo et al. (2012). Numerical results are validated against measurements from model tests on a scaled model turbine tested in a circulating water channel. To this purpose, the computational domain reproduces the test section of the facility. The turbine region is enclosed into a cylindrical grid block that rotates with respect to the rest of the grid fixed with channel walls. Suitable boundary conditions are imposed at the interface between rotating and fixed grids. Numerical results include pressure and loads distributions on turbine blades and flowfield quantities for given current speed and different values of the Tip Speed Ratio (TSR).

Pinon et al. (2012) propose a computational study of a horizontal axis turbine by a methodology based on a velocity-vorticity formulation of the Navier-Stokes equations. Turbine blades are not explicitly simulated, but their effect on the flow is accounted for through forcing terms in the momentum equation. A Lagrangian-based vortex method is used to describe the evolution of the vortical wake shed by turbine blades. Calculated velocity maps in the turbine wake are in good agreement with experimental data. 
CFD simulations of vertical-axis turbines are primarily aimed at analysing blade/wake interactions, as illustrated in Figure 15 taken from Maitre et al. (2013). Several computational studies analyse power output increase that can be achieved in VACTs by blade pitch control or similar strategies to optimise blade angle of attack over a revolution, see e.g. Hwang et al. (2009), Paillard et al. (2012) and Xiao et al. (2013). The latter use the commercial unsteady RANSE solver Fluent to simulate turbine blades with symmetrical sections and fixed or oscillating flaps at the trailing edge. Results show that power output can be increased by mitigation of boundary layer separation and shed vortex control by oscillating flaps.

The effect of diffusers on turbine performance is investigated in several papers. As an example, Luquet et al. (2013) present a study of a twin, horizontal-axis ducted rotor assembly by an unsteady RANSE model. The duct/rotor assembly is simulated under simplified assumptions (single blade rotor and cyclic conditions) to limit the computational effort. Numerical predictions show flow accelerations of $40 \%$ inside the duct. However, the authors indicate that if the power coefficient is scaled on the outer diameter of the diffuser, the power coefficient substantially drops below that of the Betz limit. Based on generated results, two duct geometries were chosen to be manufactured and tested in a towing tank.

Furthermore, Gaden and Bibeau (2010) present the results of a computational study using the commercial RANSE code ANSYS CFX of the flow around an axisymmetric shroud. Turbine induction is estimated by a simplified momentum source model and is not explicitly solved by RANSE. This turns into a computationally efficient methodology that can be used to perform parametric studies to determine duct geometries capable to maximise turbine power output for a given current energy density. The capability to achieve power output gains up to a factor 3 with respect to unducted turbine operation are determined that should require adequate experimental validation.

Unsteady loads and waves. In addition to power capturing capability, numerical models are also used to provide detailed analysis of hydrodynamic loads that are necessary to correctly design device components. Unsteady-flow models allow determination of transient loads that are generated on turbine blades over a revolution about the axis. Fluctuating blade loads are caused by nonhomogeneous, unsteady incoming flow due to many factors including device misalignment to the onset flow, high turbulence levels and velocity shear. Furthermore, the interaction between onset 
flow and turbine-induced perturbation yields complex mechanisms on turbulent structures, as discussed in Birjandi et al. (2012) for the case of a vertical-axis turbine.

The effect of free-surface waves on loading fluctuations is investigated in Lust et al. (2013) where experimental data are compared with numerical predictions by BEMT, and in Whelan et al. (2009), where tidal stream turbines are described using an actuator disc model.

Mason-Jones et al. (2013) present an experimental/computational study of the effect of velocity shear on the performance of a tidal turbine. Field measurements of the velocity profile using an Acoustic-Doppler Current profiler (ADCP) technique are used as inlet condition for a CFD analysis of turbine flow. The unsteady CFD model is based on a commercial RANSE code (ANSYS Fluent). Blade loading time histories over a revolution cycle are calculated for an isolated tri-bladed rotor and for a combined rotor/supporting stanchion assembly. Force and power fluctuations induced by the onset velocity shear and by the interaction with the stanchion are analysed revealing that a structure downstream the rotor may have an effect in terms of load peak intensity and frequency higher than the onset shear flow (Figure 16).

Reliability Particular attention is also given to assessing the reliability of current turbine blades, with fatigue and fracture identified as failure modes that are induced by loading fluctuations during operation. An example of a theoretical study on blade reliability is presented in $\mathrm{Hu}$ and $\mathrm{Du}$ (2012). A time-dependent reliability analysis for a tri-bladed horizontal-axis turbine is presented. Reliability over a 20-years life cycle is referred to excessive flap-wise bending moments calculated by a standard BEM. Blade loading predictions are based on a stochastic analysis of river current intensity. Numerical results show the effect of cut-off velocity to improve blade reliability. The study considers a river current scenario but the methodology can be extended to tidal current devices in general.

Reliability studies are particularly important in view of the assessment of non-metallic composite materials for blades. Dealing with composites, hydroelastic effects on blades are to be taken into account because of the large deflections that blade loading determine. A hydro-elastic analysis of a horizontal axis turbine is described by Nicholls et al. (2013). The Fluid-Structure Interaction model combines a lifting surface approach to predict blade loads and a structural model from the Finite Element commercial code ANSYS. Numerical results indicate that hydroelastic 
tailoring consisting of blade bend-twist coupling has a potential to reduce blade loading and to increase efficiency and reliability.

Arrays. A commercial RANSE code was used by Antheaumea et al. (2008) to describe the flow-field with a body-force method to describe turbine blades effects. Turbine-induced perturbation is represented recasting blade loading evaluated by BEM as volume forces introduced in the right hand side of the momentum equation and evaluated by BEM. The model is applied to analyse single Darrieus VACT units and arrays. Good agreement between numerical predictions and experimental data of single unit performance are obtained for TSR $>4$. Numerical applications to investigate spacing effects in a row of multiple turbines are also presented through numerical examples (Figure 17).

Environmental aspects. No less important in the development of marine current turbines is the analysis of the environmental impact of devices in terms of energy capture, radiated noise, sediment transports. Computational modelling can be used to analyse device/environment interactions by macro-scale problems where portions of regions around the device deployment site are simulated.

The impact of tidal energy extraction on sediment transportation and related seabed level changes is analysed in Neill et al. (2009, 2012) by using a 1D morphological model for the solution of mass and momentum equations combined with suitable sediment transport and bed level change models. Tidal current devices are simulated as equivalent bed-friction source terms in the momentum equations. Results of the study show that tidal energy extraction reduces the magnitude of bottom level changes and the effect is more pronounced in case of different tide intensity between tide rise and fall phases (tidal asymmetry).

The development of a 2D hydrodynamic model for coastal environment analysis based on the numerical solution of depth-integrated 3D Navier-Stokes equations is presented by Ahmadian et al. (2012). Turbines effects are modelled via source terms. The methodology is applied to simulate the impact of a notional current turbine array on current intensity outside the array and to analyse suspended sediment transportation.

Novel concepts. Finally, CFD is applied to carry on the initial validation of innovative concepts. A literature survey on this topic is not addressed here for the sake of conciseness. Recent 
studies include Amelio et al. (2012) for a novel HACT device, Gebreslassie et al. (2013) and Yang \& Lawn (2011) for novel cross-flow devices, Xiao et al. (2012) for an oscillating foil device, and Liu et al. (2013) for a flexible flapping foil.

\subsection{Validation of Numerical Modelling for Offshore Wind Turbines}

Offshore Wind Turbines (OWTs) are generally designed using simulation codes which aim to model the coupled effects of wind inflow, aerodynamics, hydrodynamics, turbine control systems and structural elasticity. These are known as aero-hydro-servo-elastic codes; some examples are shown in Table 4 (Robertson et al., 2014). Due to the high level of complexity of these codes it is desirable that they are verified and validated to ensure their accuracy. A series of research tasks have been developed under the International Energy Agency (IEA) Wind to address this need.

The first task was designated the Offshore Code Comparison Collaboration (OC3) which operates under Subtask 2 of the IEA Wind Task 23. The OC3 programme consisted of four phases each analysing a different problem. The basis of the study was a code-to-code comparison. In Phase I, the NREL 5-MW wind turbine was simulated in $20 \mathrm{~m}$ of water on a monopile with rigid foundation; in phase II the foundation was made flexible using different models to represent soilpile interactions. In Phase III, the water depth was changed to $45 \mathrm{~m}$ and the monopile was replaced with a tripod substructure; whilst in Phase IV, the wind turbine was installed on a floating sparbuoy in deep water (320 m). Full details may be found in Jonkman \& Musial, (2010).

The second task, designated the Offshore Code Comparison Collaboration, Continuation (OC4) project, extended the work of OC3 by considering the same turbine installed on two further foundations types. Phase 1 considered a jacket structure in a water depth of 50m (Popko et al. (2012), while Phase II considered a semi-submersible platform in 200m water depth (Robertson et al. 2013).

A new project by IEA Wind to initiate the validation of offshore wind modelling tools through comparison of simulated responses to physical response data from actual measurements is named the Offshore Code Comparison Collaboration, Continuation, with Correlation (OC5) as in Table 4 and will begin in 2014 and run for four years. The project will examine three structures using data from both floating and fixed-bottom systems, and from both scaled tank testing and full-scale, openocean testing. 


\section{WIND LOAD MODELLING ON WIND TURBINES}

\subsection{Uncoupled Tests}

Tank tests of bottom-mounted offshore wind turbines will often be focussed on determination of hydrodynamic loads on the support structure. In these tests, it may not be necessary to simulate the wind load and the wave/current loads simultaneously as these loads may be considered to act independently in many cases.

Where the tests aim to examine the dynamic responses of the tower and support structure in extreme weather this decoupling may be particularly appropriate, since in these conditions the turbine will typically be shut down. Hence in these cases, hydrodynamic tests can be carried out without the rotor as long as the influence of the rotor mass properties is correctly represented (e.g. de Ridder et al. (2011)).

Measurement of wave / current loads without simulation of wind loads offers a number of advantages. Facilities without wind generation may be employed, set-up and calibration time will be reduced, whilst a larger model can be used for the measurements of wave/current loads. Furthermore, measurement uncertainty may be reduced since the entire range of the load measurement systems can be used for measuring the wave/current loads. However, where tests are aimed at investigating the coupled dynamic response of the structure in operational conditions, including realistic modelling of flexibility and aerodynamic damping, then inclusion of the aerodynamic coupling due to the rotor is necessary.

In studies of floating offshore wind turbines, model tests without the rotor can be carried out at preliminary stages of the tests or for special purposes, such as comparison of different support structures in terms of their responses to waves, or for the validation of numerical models. However, final tests aiming at evaluating the global response of the system from the concept validation stage to the prototype and demonstration stage should include at least simplified modelling of the rotor due to the strong coupling present between the platform dynamics and the rotor-generated forces and moments. 


\subsection{Simplified Coupled Aero-Hydrodynamic Tests}

The forces and moments generated by the rotor are partly aerodynamic in nature, but additional moments are generated due to gyroscopic effects; for example, pitch motions of a horizontal-axis turbine facing into wind and waves will generate gyroscopic moments around the yaw axis.

It should be emphasized here that the aim of modelling the rotor loads in hydrodynamic testing of offshore wind turbines is normally not to determine the power captured by the turbine. Instead the goal is to model rotor loads sufficiently accurately to allow for correct evaluation of the global response of the system.

Simplified Simulation without Wind Generation. A number of methods may be employed to simulate the presence of the rotor without using a direct representation of the rotor aerodynamics, although none capture all of the physics of the fully-coupled system.

In the simplest case, the steady wind load may be simulated using a lightweight line attached at the rotor hub (for a horizontal axis system) and tensioned using a weight to simulate the steady aerodynamic thrust. However this approach neglects the aerodynamic damping imparted by the rotor on the system as well as the gyroscopic effects and the steady torque; furthermore, the total mass and moments of inertia of the system will inevitably be incorrect. This approach can only be justified for rough estimation of the maximum mooring offset (e.g. Chujo, et al. (2011)).

A further possibility, which may be suitable for small-scale tests in the concept validation stage, is to use the rotor as a fan rotating in otherwise stationary air (e.g. Kraskowski (2012)). This offers a rather simplified approach to the investigation of response of FOWTs in facilities which do not have wind generation capabilities. In this case, separate measurements are required to calibrate the system, i.e. to identify the force vs. rpm characteristics.

This method of modelling the rotor is quite simple and allows for easy adjustment of the mean wind load. However, it is difficult with this approach to control the blade pass frequency and wind load simultaneously to achieve the correct mean thrust and torque whilst capturing tower interaction 
effects. Further challenges of this approach include the correct simulation of orientation of gyroscopic moments in relation to steady moments, and the difficulty in realistically simulating the behaviour of the magnitude and direction of the thrust vector as the turbine pitches. Particular care is required in the interpretation of results from this type of test.

Simplified Simulation with Wind Generation. Where a simulated wind field may be created in a tank, it is possible that a solid or porous disc may be used in place of the rotor in conjunction with a battery of fans. The disc should be sized to generate a drag load in the simulated wind field corresponding to the predicted mean thrust on the turbine. If a rotating disc is employed with Froude-scaled rotary moment of inertia, and rotation speed, it is possible to capture the coupled response of the structure taking into account the gyroscopic coupling between the rotor and the platform. Alternatively, a separate rotating arm may be deployed downwind of the disc (see Cermelli et al. (2009)).

This approach neglects the aerodynamic torque exerted by the rotor on the platform as well as blade / tower interactions; problems may result due to the unsteadiness of the flow around the disc when pitching in waves.

\subsection{Direct simulation of the rotor in fully coupled tests.}

Direct modelling of a floating offshore wind turbine rotor is usually realized by exposing a working rotor to a wind field generated by a battery of fans. This method allows for the most accurate modelling of actual conditions of the rotor operation and is recommended to be used whenever possible. Examples are given in Chujo et al. (2011) for a spar OWT, Shin et al. (2013) for a semi-submersible OWT and Goupee et al. (2012), for spar, semi-submersible and TLP. The rotor rpm and the spatial variation of wind speed should be carefully calibrated prior to the main experiments.

Particular challenges in this approach with respect to the wind generation include the generation of wind field over the large volumes required due to the size of the models, especially where tests are intended to include the representation of wind gradients and the wind turbulence (see section 5.6). A further challenge is the difficulty of generating wind in a wave tank close to a wavy water 
surface, particularly in tests with large waves. The design of a wind system for use over a wave tank is discussed by De Ridder et al. (2013).

The minimum aerodynamic requirement for modelling the presence of rotor in a fully-coupled test of a floating offshore wind turbine is the correct reproduction of the mean wind thrust load in order to generate correct aerodynamic overturning moments and mooring offsets. The impact of rotor aerodynamics on pitch damping is also of great importance.

Maintaining the Reynolds similarity is in general not possible for typical sizes of basin models, and thus detailed modelling of aerodynamics, including stall phenomena, is usually infeasible. Variations in wind speed caused by motions of a floating platform will in any case naturally be driven by wave effects governed by Froude similarity.

Depending on the required outcome of the tests, modelling the rotor will usually also require maintaining the Froude similarity for the rotor RPM to generate the correct representation of the gyroscopic effect of the rotor as well to allow more accurate representation of the aerodynamic interaction between the rotor and the support structure. This will also involve realistic representation of the mass distribution and possibly the elasticity of supporting structure and rotor blades.

Performance models of OWTs will therefore normally be scaled using Froude similitude. However some key parameters related to wind loading will not scale in this manner, leading to scale effects when extrapolating to full-scale, particularly for FOWTs. Approaches to address this through redesign of the rotor model are discussed in more detail in section 5.4.

\subsection{Physical Modelling of Rotor Aerodynamics}

In wind/wave tank model tests of FOWTs, the difficulty in achieving flow similarity between model and prototype increases drastically with increases the scale ratio. As mentioned in section 1.4, the increasing size of modern wind turbines designed for offshore deployment results in scale ratios in the region of $1 / 50-1 / 200$. The application of Froude similarity to the steady wind speed results in substantially incorrect modelling of the rotor aerodynamics due to Reynolds number dissimilitude. 
The low Reynolds Number conditions can cause substantially dissimilar flows with the relatively thick sections often employed in offshore wind turbines, due to effects such as laminar separation, leading to reduced lift and increased drag, and unrealistically low thrust and torque coefficients compared to the full-scale foils. The small model size also results in increasing influence of any imperfections in geometric representation on the flow quality (Muthanna et al., 2013).

The most important forces generated on the rotor and contributing to global response of the FOWT are: gyroscopic moments, rotor thrust and rotor torque. In order to match the thrust and torque correctly, it is necessary to modify the rotor and/or the mean wind speed to correct for the Reynolds number dissimilitude. It is generally difficult to reproduce both thrust and torque correctly, hence priorities must be set; generally this will involve prioritising attempting to match the thrust correctly.

Martin et al. (2012) discuss three possible approaches to address this challenge. In the first approach, the wind speed is increased beyond the Froude-scaled value to compensate for the low thrust coefficient. If rotor speed is maintained at Froude-scaled values, to retain correct gyroscopic moments, then the tip-speed ratio will be incorrect, resulting in incorrect torque. However this may be justified as an approximation since the overturning moment due to thrust is typically very much greater than that due to torque. The ratio of unsteady velocity (caused by platform motions) to mean velocity will be reduced leading to incorrect modelling of effects of unsteady inflow on the rotor. Nonetheless, results show that the aerodynamic damping of the platform pitch generated by the turbine is modelled with a reasonable degree of accuracy.

A second approach addressing low Reynolds number effects is the placement of studs or other roughened materials as a turbulence stimulator along the leading edge of a blade; however this is unlikely to improve the turbine performance adequately on its own to yield comparable performance with the full-scale device, and can yield unrealistic results if laminar separation occurs, as well as unrealistic unsteady aerodynamic loads during flow re-attachment.

A third possible approach is to redesign the rotor blade sections to account for Reynolds number effects, or even more radical solutions such as changing the number of blades and the rotor 
diameter. This can involve choice of laminar flow sections for the model scale rotor so that the model rotor design can simulate as closely as possible the correct full-scale mean thrust and torque coefficients at the model-scale Reynolds Number (based on blade chord), whilst still maintaining the correct mass properties. Martin et al. (2012) demonstrate an example in which blades were redesigned using low Reynolds number aerofoils. These sections are less susceptible to laminar separation under low Reynolds number conditions, leading to broadly correct values of scaled thrust and aerodynamic damping using Froude-scaled wind speed. A further example of this technique is given by De Ridder et al. (2013).

Correct modelling of the gyroscopic moments introduced by the rotor can be achieved by Froude scaling of the mass properties and rotor speed. However, modelling the mass properties of the rotor at small scale will require lightweight materials of high strength potentially presenting some severe challenges in manufacture. For example, the 1:80 scale blades shown in Figure 18 have a target mass of only 35g. It can be difficult to achieve the necessary combination of accurate geometry and very low mass using conventional model making techniques, and novel approaches may be required: for example, film-coated blades may be manufactured from components created by a $3 \mathrm{D}$ printer to achieve both mass and elasticity requirements.

Contribution of the wind load to global response of the FOWT is also strongly affected by the pitch control strategy of the turbine. In the near future, it is possible that 3D printers will enable the manufacture of both very light weight models of the RNA (rotor nacelle assembly) and the reproduction of the complex active blade pitch control system. Some examples of successful model tests of FOWTs in wind and waves including direct modelling of the blade pitch control system were reported by Chujo et al. (2013) and De Ridder et al. (2013).

\subsection{Software-in-the-loop simulations of floating offshore wind turbines}

Several studies of floating offshore wind turbines have utilised the "software-in-the-loop" idea in which an active control system drives an actuator in real time to generate some of the forces in a model test, usually with the aim of simulating forces which cannot be scaled correctly in a model test. Examples in recently published literature include tests in which the unsteady aerodynamic thrust force in a hydrodynamic test is generated by a speed-controlled fan based on measurement of the instantaneous velocity at the nacelle (e.g. Zamora-Rodriguez et. al., 2014) or those in which the 
hydrodynamic motions of a floating platform are simulated in a wind tunnel using a hexapod (Bayati et. al. 2014).

The technique offers a potential solution to overcome the challenging scaling problems related to discrepancies between Reynolds and Froude scaling for the aerodynamic and hydrodynamic forces on a floating offshore wind turbine. Technical challenges which must be overcome in order to implement these approaches include generating adequate forces in each direction of interest, and obtaining sufficiently rapid response of the actively-controlled system.

Furthermore there is always the limitation that the response of the controlled system is at best only as good as the mathematical model used to control it, and thus the model test lacks the completely physical nature of a conventional test. Nonetheless, given that these techniques are only used in cases in which a fully physical model test already involves scaling compromises, they appear to offer an interesting and promising route to improved testing methodologies.

\subsection{Wind characteristics for design load calculations}

Key issues for design load calculations include the choice of models for wind gradient and the turbulence. Obrhai (2012) reviews the current guidelines for wind modelling for offshore wind turbines.

The IEC standard 64100-3 (2009) recommend that the wind speed profile as a function of height is given by the power law:

$$
V(z)=V_{\text {hub }}\left(z / z_{\text {hub }}\right)^{\alpha}
$$

where, for normal wind conditions, the power law exponent, $\alpha$, is taken as 0.14 . The same standard gives the option for the stochastic turbulence models of using the Kaimal spectral and the exponential coherency model:

$$
\frac{f S_{\mathrm{k}}(f)}{\sigma_{\mathrm{k}}^{2}}=\frac{4 f L_{\mathrm{k}} / V_{\text {hub }}}{\left(1+6 f L_{\mathrm{k}} / V_{\text {hub }}\right)^{5 / 3}}
$$




$$
\operatorname{Coh}(r, f)=\exp \left[-8,8\left(\left(f \times r / V_{\text {hub }}\right)^{2}+\left(0,12 r / L_{c}\right)^{2}\right)^{p, 5}\right]
$$

\section{UNCERTAINTIES IN PHYSICAL MODEL EXPERIMENTS AND EXTRAPOLATION TO FULL-SCALE}

Whilst extensive studies have been made in the marine renewable energy literature of the uncertainty of energy resource and of the economics renewable energy, there are relatively few examples of thorough uncertainty analyses of hydrodynamic tests and/or extrapolation to full-scale. This is perhaps surprising given the importance of understanding the accuracy of the prediction of power capture of devices in predicting the cost of energy generated.

Whilst standard procedures specifically addressing MRE devices have not been developed, some aspects of uncertainty analysis for hydrodynamic tests of MRE devices may be inferred from existing ITTC procedures. For example, the uncertainty in the loading on a horizontal axis current turbine may be assessed using a variation of the approach set out in ITTC Recommended Procedure 7.5-02-03-02.2 Uncertainty Analysis, Example for Open Water Test (ITTC (2014e), Milne et al. (2013)). Similarly the motions of floating wave or current energy devices or floating wind turbines can be assessed using a modified version of the approach set out in ITTC Recommended Procedure 7.5-02-07-02.1 Seakeeping Experiments, (ITTC (2014f)), whilst measurements of flow around devices may be directly addressed using approaches such as described in ITTC Recommended Procedure 7.5-01-03-03 Uncertainty Analysis: Particle Imaging Velocimetry (PIV) (ITTC (2014g)). An example of such an analysis is given in Fleming et al. (2013) for PIV measurements of the flow inside an Oscillating Water Column wave energy device. However there are some very specific challenges in relation to the analysis of uncertainty of power output of MRE devices which are not addressed by existing procedures. These are discussed further below.

Arguably the area in which greatest development is required is in the prediction of power from wave energy devices. Very few examples exist in the literature of uncertainty analysis of wave energy device tests. Lamont-Kane et al. (2013) address the model-scale uncertainty in a variety of parameters associated with small-scale model tests of an idealised heaving buoy device both as a single point absorber and in a square array of four devices. Results show a model-scale uncertainty in power capture for a single test of $8-10 \%$ which could be reduced to $2-3 \%$ by using multiple 
repeat tests; however even then, the uncertainty could be of an order of magnitude similar to the array interactions.

In general there are several key challenges to be addressed in the assessment of uncertainty for full-scale power capture predictions. One of the key issues affecting uncertainty of the model-scale results for a wave energy device is the simulated Power Take-Off system, as discussed in detail in section 3.2 In tests at low TRLs, it is unlikely that the full-scale PTO has been designed in detail, and hence any model-scale PTO simulator will be idealised. Nonetheless it is important to estimate the uncertainty in the behaviour of the idealised system in order including effects of static or dynamic friction, and hydraulic or pneumatic systems.

This may be achieved using a PTO test rig as discussed in section3.2; data from these tests may be used to inform the uncertainty in the model dynamics. Other aspects of the tests which require particular care are the uncertainties in the model-scale wave conditions, related to temporal and spatial variations through the tank; these have particular significance where array tests are carried out, since the "footprint" of the array will often be substantially larger than other single structures typically tested.

The impact of wave blockage on results should be carefully considered; guidance for other structures (such as offshore platforms), which are generally designed so that interaction with waves is small, may not be well-suited to wave energy devices which are designed to maximise energy extraction from the waves. Ersdal \& Moe (2013) discuss the impact of tank width on power capture of a floating wave energy device. For some devices, there may be issues related to model manufacture. Achieving the desired mass properties (where they are known) may be challenging for floating bodies due to limits on size of PTO components, whilst scaling material properties of flexible structures is often difficult.

For all types of devices additional uncertainty results from extrapolation of model-scale results to full-scale, particularly in cases in which multiple scaling ratios are relevant. This affects wave energy devices with PTOs which do not behave according to Froude scaling, such as oscillating water columns, floating or mid-water current turbine systems and floating offshore wind turbines, for which for which both Froude and Reynolds scaling are relevant, as discussed in sections 3.3 and 5. 
In many cases the environmental conditions simulated in the tank tests will be based on rather limited data for the general area intended for the device deployment, or at best, data gathered from one or two locations in the proposed site. Issues such as wave spreading, unsteady flow characteristics, and turbulence levels may well not be characterised in detail at the point at which the tests are carried out, leading to additional uncertainty in the predictions of energy capture from working devices at sea.

The final significant challenge is that there is no large-scale open-sea data publically available for validation of model-test and extrapolation procedures. Without this data the sensitivity of the uncertainty to the different factors of model-scale test procedures, the scaling approaches, and environmental data cannot be validated, and the procedures cannot sensibly be refined systematically to reduce uncertainty.

\section{CONCLUSIONS}

The offshore renewable industry is evolving rapidly with activity in one or more of the three sectors (wave, current and wind) in many regions worldwide. Offshore wind is commercially well established in near-shore regions, and there is swift progress towards far offshore commercial exploitation, leading to rapid evolution of fixed and floating support structures, installation approaches and maintenance systems. Current energy devices have been extensively tested at sea and the first generation of commercial tidal arrays is starting to take shape. Commercial exploitation of wave energy appears to be further in the future, although a number of full-scale sea trials have been implemented.

There is a general lack of availability of full-scale or large-scale data from all types of device with which physical testing or numerical modelling methodologies can be validated. Relatively few full-scale trials have been performed compared to other application areas, and the vast majority of results are confidential for commercial reasons. Only a few well-established test centres have diverse experience in methodology for field testing.

The demand for physical testing and numerical modelling of offshore renewable devices appears likely to continue to grow in the short to medium term, and it is expected that methodologies for 
physical and numerical modelling will continue to develop. A variety of bodies is developing standards relating to offshore renewable energy, though in many cases these are not focussed on hydrodynamics aspects involving physical testing or numerical modelling of devices.

At present many areas remain which lead to modelling uncertainties. Key challenges for modelling wave devices include adequate representation of Power Take-Off systems and modelling of large motions of complex articulated or flexible structures. Scale effect, the impact of low model scale Reynolds number, and the behaviour in unsteady flow are key challenges for modelling of current turbines. Adequate representation of the coupling between the complex system of steady and unsteady aerodynamic, hydrodynamic and gyroscopic forces, along with the structural response of the tower and blades and the dynamics of the control system, present substantial challenges for the modelling of floating wind turbines, with further difficulties in physical testing related to generation of high-quality wind fields over an ocean basin, and the construction of large and extremely lightweight models.

\section{References}

Alam M.R., 2012, Nonlinear analysis of an actuated seafloor-mounted carpet for a high performance wave energy extraction, Proceedings of the Royal Society Series A. Vol. 468 pp 31533171

Ahmadian, R., Falconer, R., Bockelmann-Evans, B., 2012, Far-field modelling of the hydroenvironmental impact of tidal stream turbines. Renewable Energy, Vol. 38, pp. 107-116.

Amelio, M., Barbarelli, S., Florio, G., Scornaienchi, N.M., Minniti, G., Cutrupi, G., SánchezBlanco, M., 2012, Innovative tidal turbine with central deflector for the exploitation of river and sea currents in on-shore installations. Applied Energy, Vol. 97, pp. 944-955.

Antheaumea, S., Ma1tre, T., Achard, J.-L., 2008, Hydraulic Darrieus turbines efficiency for free fluid flow conditions versus power farms conditions. Renewable Energy, Vol. 33, pp. 2186-2198. 
Babarit A., Duclos G., Clément A.H., 2004, Comparison of latching control strategies for a heaving wave energy device in random sea, Applied Ocean Research, Vol 26 (5), 227-238

Babarit A., Clément A.H., Gilloteaux J.C., 2005, Optimization and time domain simulation of the SEAREV wave energy converter, Proceedings, $24^{\text {th }}$ International Conference on Offshore Mechanics and Artic Engineering, Kalikidiki, Greece

Babarit A. and Clément A.H., 2006, Optimal latching control of a wave energy device in regular and irregular waves, Applied Ocean Research, Vol 128 (1), pp 56-64

Babarit A., Guglielmi M., Clément A.H., 2009, Declutching control of a wave energy converter, Ocean Engineering, Vol 36 (12), pp 1015-1024

Babarit A., Mouslim H., Clément A.H., Laporte-Weywada P., 2009, On the numerical modelling of the non-linear behaviour of a wave energy converter, Proceedings, $28^{\text {th }}$ Int. Conf. on Offshore Mechanics and Artic Engineering, Honolulu, USA

Babarit A., Hals J., Muliawan M.J., Kurniawan A., Moan T., Krokstad J., 2012, Numerical benchmarking study of a selection of wave energy converters, Renewable Energy, Vol 41, pp 44-63

Babarit A., 2013, On the park effect in arrays of oscillating wave energy converter, Renewable Energy, Vol 58, pp 68-78

Babarit A., Gendron B., Singh J., Melis C., Jean P., 2013, Hydro-elastic modelling of an electroactive wave energy converter, Proceedings, $32^{\text {nd }}$ International Conference on Offshore Mechanics and Artic Engineering, Nantes, France

Bahaj, A.S., Batten, W.M.J., McCann, G., 2007a, Experimental verifications of numerical predictions for the hydrodynamic performance of horizontal axis marine current turbines, Renewable Energy, Vol. 32 2007) pp 2479-2490. 
Bahaj AS, Molland AF, Chaplin JR, Batten WMJ., 2007b, Power and thrust measurements of marine current turbines under various hydrodynamic flow conditions in a cavitation tunnel and a towing tank, Renewable Energy 2007; Vol 32(3): pp. 407-426.

Baltazar, J., Falcão de Campos, J.A.C., 2008, Hydrodynamic analysis of a horizontal axis marine current turbine with a boundary element method, Proceedings, ASME 27th Conference on Offshore Mechanics and Arctic Engineering (OMAE), ASME, Estoril, Portugal, 2008, pp. 883-893.

Banks, D., van't Hoff, J., \& Doherty, K., 2013, The Development of an Experimental Force Feedback Dynamometer to investigate the real Time Control of an Oscillating Wave Surge Converter, Paper OMAE2013-10766 Proceedings, 32nd Int. Conf. on Ocean, Offshore and Arctic Engineering (OMAE2013) June 9-14, 2013, Nantes, France

Bayati, I., Belloli, M., Ferrari, D., Fossati, F. \& Giberti, H., 2014, 'Design of a 6-DoF Robotic Platform for Wind Tunnel Tests of Floating Wind Turbines‘ Energy Procedia, Vol 53, 2014, Pages 313-323

Bellamy N.W., Peatfield A.M., 1986, Design and performance of the circular sea clam wave energy converter, Proceedings, $3^{\text {rd }}$ International Symposium on wave, tidal, OTEC and small scale hydro energy

Berge H., 1982, Wave energy utilization Proceedings, $2^{\text {nd }}$ International Symposium on Wave Energy Utilization, Norwegian Institute of Technology, Trondheim, Norway, June 22-24

Bhinder M., Babarit A., Gentaz L., Ferrant P., 2011, Assessment of viscous damping via 3DCFD modelling of a floating wave energy device, Proceedings, $9^{\text {th }}$ European Wave and Tidal Energy Conference, Southampton, UK

Birjandi, A.H., Woods, J., Bibeau, E.L., 2012, Investigation of macro-turbulent flow structures interaction with a vertical hydrokinetic river turbine, Renewable Energy, Vol. 48 2012) pp. 183192. 
Bjarte-Larsson, T. and Falnes J., 2006, Laboratory experiment on heaving body with hydraulic power take-off and latching control, Ocean Engineering Vol 33 pp. 847-877

Brito e Melo A., and Huckerby J. Editors, 2012, Ocean Energy Systems (OES) Annual Report 2012

Borgarino B., Kofoed J.P., Meinert P., 2007, Development of a generic power simulation tool for overtopping based WEC, DCE Technical report 35, Aalborg University, Department of Civil Engineering

Budal K. and Falnes J., 1974, A resonant point absorber of ocean-wave power, Nature, Vol. 256, pp 478-479

Budal K., 1977, Theory of absorption of wave power by a system of interacting bodies, Journal of Ship Research, Vol 21, 248-253

Cermelli, C., Roddier, D. and Aubault, A., 2009, Windfloat: A Floating Foundation for Offshore Wind Turbines Part II: Hydrodynamic Analysis, Proceedings, 28th International Conference on Ocean, Offshore and Arctic Engineering OMAE2009-79231, Honolulu, Hawaii, USA

Chujo T., Ishida S., Minami Y., Nimura T., and Shunji Inoue S., 2011, Model Experiments on the Motion of a SPAR Type Floating Wind Turbine in Wind and Waves, Proceedings, 30th International Conference on Ocean Offshore \& Arctic Engineering, OMAE 2011-49793 Rotterdam, The Netherlands

Clément A.H. and Babarit A., 2012, Discrete control of resonant wave energy devices, Proceedings, Philosophical Transactions of the Royal Society A, Vol 370, pp 288-314

Cretel J., Lewis A.W., Lightbody G., Thomas G.P., 2010, An application of model predictive control to a wave energy point absorber, Proceedings, IFAC conference on control methodologies and technology for energy efficiency, 267-272 
Crétel J.A.M., Lightbody G., Thomas G.P., Lewis A.W., 2011, Maximisation of energy capture by a wave energy point absorber using model predictive control, Proceedings, $18^{\text {th }}$ IFAC world congress, Milano, Italy

Cruz J., 2008) Ocean wave energy: Current Status and Future Perspectives, Springer, ISBN 9783-540-74895-3

De Ridder, E., Aalberts, P. van den Berg, J. Buchner, B, Peeringa, J., 2011, The Dynamic Response of an Offshore Wind Turbine with Realistic Flexibility to Breaking Wave Impact, Proceedings, $30^{\text {th }}$ International Conference on Ocean Offshore \& Arctic Engineering, OMAE 201149563 Rotterdam, The Netherlands

De Ridder, E.-J., Otto, W., Zondervan, G.-J., Huijs, F., Savenije, F., 2013, State of the Art Model Testing Techniques for Floating Wind Turbines, Proceedings, EWEA Offshore 2013, Frankfurt, Germany

Durand M., Babarit A., Pettinotti B., Quillard O., Toularastel J.L., Clément A.H., 2007, Experimental validation of the performances of the SEAREV wave energy converter with real time latching control, Proceedings, $7^{\text {th }}$ European Wave and Tidal Energy conference, Porto, Portugal

Ersdal, S. \& Moe, A. M., 2013, Model Test of the Aker Wave Energy Converter Concept. Paper OMAE-10537 Proceedings, 32nd Int. Conf. on Ocean, Offshore and Arctic Engineering (OMAE2013) June 9-14, 2013, Nantes, France

Evans D.V., 1976, A theory for wave-power absorption by oscillating bodies, Journal of Fluid Mechanics, Vol. 77, pp 1-25

Evans D.V., 1979, Some theoretical aspects of three dimensional wave energy absorbers. Proceedings, $1^{\text {st }}$ Symposium on Wave Energy Utilization, Gothenburg, Sweden

Evans D.V. and Falcao A.F. de O. 1985, Hydrodynamics of Ocean Wave-Energy Utilization, Proceedings, IUTAM Symposium Lisbon, Portugal 
Falcao A.F. de O., 2007, Modelling and control of oscillating-body wave energy converters with hydraulic power take-off and gas accumulator, Ocean Engineering, Vol 34, 2021-2032

Falcao A.F. de O, 2009, Wave energy utilization: a review of the Technologies, Renewable and Sustainable Energy Reviews

Falcao A.F. de O., Henriques J.C.C., Candido J.J., 2012, Dynamics and optimization of the OWC spar buoy wave energy converter, Renewable Energy, Vol 48, 369-381

Falcão de Campos, J.A.C., 2007, Hydrodynamic Power Optimization of a Horizontal Axis Marine Current Turbine with Lifting Line Theory, Proceedings, 17th International Offshore and Polar Engineering Conference, Vol. 1, pp. 307-313.

Falnes J., 1980, Radiation impedance matrix and optimum power absorption for interacting oscillators in surface waves. Applied Ocean Research, Vol 2, 75-80

Falnes J., 2002, Ocean waves and Oscillating Systems, Cambridge University Press. ISBN 0$521-78211-2$

Falnes J., 2007, A review of wave energy extraction, Marine Structures, Vol. 20, pp 185-201

Farley F. J. M., Rainey R. C. T., Chaplin J. R., 2011, Rubber tubes in the sea, Proceedings Philosophical Transactions of the Royal Society Series A Vol. 370, pp 381-402.

Ferreira CS, Kuik GV, Bussel GV, Scarano F. 2009, Visualization by PIV of dynamic stall on a vertical axis wind turbine, Experiments in Fluids Vol 46 pp 97-108.

Fleming, A., Penesis, I., Goldsworthy, L., Macfarlane, G. Bose, N. \& Denniss, T., 2013, Phase Averaged Flow Analysis in an Oscillating Water Column Wave Energy Converter, J. Offshore Mech. \& Arctic Eng. Vol. 135 
Folley M., Whittaker T.J.T., van’t Hoff J., 2007, The design of small seabed-mounted bottomhinged wave energy converters, Proceedings, $7^{\text {th }}$ European Wave and Tidal Energy Conference, Porto, Portugal

Folley M., Whittaker T.J.T., Henry A., 2007, The effect of water depth on the performance of a small surging wave energy converter, Ocean Engineering, Vol 34, 1265-1274

Folley M. and Whittaker T.J.T., 2009, Analysis of the Nearshore Wave Energy Resource, Renewable Energy, Vol. 34 (7) pp 1709-1715

Folley M., Babarit A., Child B., Forehand D., O’Boyle L., Silverthorne K., Spinneken J., Stratigaki V., Troch P., 2012, A Review of Numerical Modelling of Wave Energy Converter Arrays, Proceedings, $31^{\text {st }}$ International Conference on Offshore Mechanics and Arctic Engineering, Rio de Janeiro, Brazil.

Fontaine, A., Straka, W., Meyer, R., Jonson, M., 2013, A 1:8.7 Scale Water Tunnel Verification \& Validation of an Axial Flow Water Turbine Technical Report Pennsylvania State University and Sandia National Laboratories (SNL). 122 pp

Forestier, J. M., Holmes, B., Barret, S. and Lewis, A., 2007, Value and validation of small scale physical model tests of floating wave energy converters, Proceedings, 7th European Wave and Tidal Energy Conference, Porto, Portugal, 11-14th Sep. 2007.

Fraenkel P.L., 2010, Development and testing of Marine Current Turbine’s SeaGen 1.2 MW tidal stream turbine, Proceedings, 3rd International Conference on Ocean Energy (ICOE), Bilbao, Spain 2010.

Fusco F. and Ringwood J., 2012, A study of the prediction requirements in real-time control of wave energy converters', IEEE Transactions on sustainable energy, Vol 3(1), pp 176-184

Gaden, L.F., Bibeau, E.L., 2010, A numerical investigation into the effect of diffusers on the performance of hydro kinetic turbines using a validated momentum source turbine model, Renewable Energy, Vol. 35 2010, pp. 1152-1158. 
Gaurier, B., Davies, P., Deuff, A., Germain, G., 2013, Flume tank characterization of marine current turbine blade behaviour under current and wave loading, Renewable Energy 59 2013, pp. 112

Gebreslassie, M.G., Tabor, G.R., Belmont, M.R., 2013, Numerical simulation of a new type of cross flow tidal turbine using OpenFOAM. Part I: Calibration of energy extraction Renewable Energy, Vol. 50 2013, pp. 994-1004.

Gilloteaux J.C., Babarit A., Ducrozet G., Durand M., Clément A.H., 2007, A non-linear potential model to predict large-amplitudes-motions : application to the SEAREV wave energy converter, Proceedings, $26^{\text {th }}$ International Conference on Offshore Mechanics and Arctic Engineering, San Diego, USA

Girard, Père et fils, 1799, Brevet d'invention de quinze ans pour divers moyens d'employer les vagues de la mer, Patent.

Gomes R. P. F., Henriques J. C. C., Gato L. M. C., Falcao A.F. de O., 2011, Design of a floating oscillating water column for wave energy conversion, Proceedings, $9^{\text {th }}$ European Wave and Tidal Energy Conference, Southampton, UK

Goupee A.J., Koo B., Kimball R.W., Lambrakos K.F., and Dagher H.J., 2012, Experimental Comparison of Three Floating Wind Turbine Concepts, Proceedings, 31th International Conference on Ocean Offshore \& Arctic Eng., OMAE2012-83645 Rio de Janeiro, Brazil

Greenhow M., Rosen J.H., Reed M., 1984, Control Strategies for the Clam Wave Energy Device, Applied Ocean Research, Vol 6(4), 197-206

Guerber E., Benoit M., Grilli S.T., Buvat C., 2012, A fully nonlinear implicit model for wave interactions with submerged structures in forced or free motion, Engineering Analysis with Boundary Elements, Vol 36 (1), pp 1151-1163 
Hals J., Bjarte-Larsson T., Falnes J., 2002, Optimum reactive control and control by latching of a wave-absorbing submerged heaving sphere, Proceedings, $21^{\text {st }}$ International Conference on Offshore Mechanics and Arctic Engineering, Oslo, Norway

Hansen, R. H and Kramer M. M., 2011, Modelling and Control of the Wavestar Prototype Proceedings, 9th European Wave and Tidal Energy Conference (EWTEC 20011), Southampton, UK

Henderson R., 2005, Design, simulation and testing of a novel hydraulic power take-off system for the Pelamis wave energy converter, Renewable Energy, Vol 31(2), 271-283

Hu, Z., Du, X., 2012, Reliability analysis for hydrokinetic turbine blades, Renewable Energy, Vol. 48, pp. 251-262.

Hwang, I.S., Lee, Y.H., Kim, S.J., 2009, Optimization of cycloidal water turbine and the performance improvement by individual blade control, Applied Energy, Vol. 86, 1532-1540.

IEC 61400-3 2009, Wind Turbines - Part 3: Design Requirements for Offshore Wind Turbines, IEC Standard

ITTC Specialist Committee on Hydrodynamic Modelling of Marine Renewable Energy Devices, 2014, Final Report and Recommendations to the $27^{\text {th }}$ ITTC Proc $27^{\text {th }}$ International Towing Tank Conference, Copehagen, Denmark, Vol 2 pp680-725

ITTC 7.5-02-07-03.7 (2014b) Recommended Guideline: Wave Energy Converter Model Test ITTC Guideline 13pp.

ITTC 7.5-02-07-03.8 (2014c) Recommended Guideline: Model Tests for Offshore Wind Turbines ITTC Guideline 16pp.

ITTC 7.5-02-07-03.9 (2014d) Recommended Guideline: Model Tests for Current Turbines ITTC Guideline 18pp. 
ITTC 7.5-02-03-02.2 (2014e) Recommended Procedures and Guidelines: Uncertainty Analysis, Example for Open Water Test ITTC Guideline 11pp.

ITTC 7.5-02-07-02.1 (2014f) Recommended Procedures and Guidelines: Seakeeping Experiments ITTC Guideline 13pp.

ITTC 7.5-01-03-03 (2014g) Uncertainty Analysis: Particle Imaging Velocimetry (PIV). ITTC Guideline 18pp.

ITTC Specialist Committee on Surface Treatment, Final report and recommendations to the 26th ITTC, 2011, Final Report and Recommendations to the $26^{\text {th }}$ ITTC Proc $26^{\text {th }}$ International Towing Tank Conference, Rio de Janeiro, Brazil, Vol. 2 pp 419-475

Jo, C.H., Yim, J.Y., Lee, K.H., Rho, Y.H,, 2012, Performance of horizontal axis tidal current turbine by blade configuration, Renewable Energy, Vol. 42, pp. 195-206.

Jonkman, J., \& Musial, W., 2010, Offshore Code Comparison Collaboration (OC3) for IEA Task 23 Offshore Wind Technology and Deployment, Technical Report NREL/TP-5000-48191 71 pp

Josset C., Babarit A., Clément A.H., 2007, A wave to wire model of the SEAREV wave energy converter, Proceedings. Institution of Mechanical Engineers, Part M. Journal of Engineeering for the Maritime Environment., Vol. 221, pp 81-93

Kerbiriou M.A., Prevosto M., Maisondieu C., Babarit A., Clément A.H., 2007, Influence of an improved sea-state description on a wave energy converter production, Proceedings, $26^{\text {th }}$ International Conference on Offshore Mechanics and Arctic Engineering, San Diego, USA

Khan, M.J., Bhuyan, G., Iqbal, M.T., Quaicoe, J.E., 2009, Hydrokinetic energy conversion systems and assessment of horizontal and vertical axis turbines for river and tidal applications: A technology status review, Applied Energy, Vol. 86, pp 1823-1835. 
Kraskowski, M., Zawadzki, K., Rylke, A., 2012, A Method for Computational and Experimental Analysis of the Moored Wind Turbine Sea-keeping, Proceedings, 18th Australasian Fluid Mechanics Conference, Launceston, Australia

Kurniawan A., Hals J., Moan T., 2011, Modelling and simulation of a floating oscillating water column, Proceedings, $30^{\text {th }}$ International Conference on Ocean, Offshore and Artic Engineering, Rotterdam, The Netherlands

Lamont-Kane, P., Folley, M. \& Whittaker, T., 2013, Investigating Uncertainties in Physical Testing of Wave Energy Converter Arrays, Proceedings, 10th European Wave and Tidal Energy Conference (EWTEC 2013), Aalborg, Denmark

Li, Y., Calisal, S.M., 2010a, Three-dimensional effects and arm effects on modeling a vertical axis tidal current turbine, Renewable Energy, Vol. 35, pp 2325-2334.

Li, Y., Calisal, S.M., 2010b, Modeling of twin-turbine systems with vertical axis tidal current turbine: Part I - Power Output, Ocean Engineering, Vol. 37, pp 627-637.

Li, Y., Calisal, S.M., 2011, Modeling of twin-turbine systems with vertical axis tidal current turbine: Part II - torque fluctuation, Ocean Engineering, Vol. 38, pp 550-558.

Liu, W., Xiao, Q. \& Cheng, F., 2013, A bio-inspired study on tidal energy extraction with flexible flapping wings, Bioinspiration and Biomimetics, Vol 8, No. 3

Lovas S., Mei C.C., Liu Y., 2010, Oscillating water column at a coastal corner for wave power extraction, Applied Ocean Research, Vol 32, pp 267-283

Luquet, R., Bellevre, D., Fréchou, D., Perdon, P., Guinard, P., 2013, Design and model testing of an optimized ducted marine current turbine, International Journal of Marine Energy, Vol. 2, pp 61-80. 
Lust, E., Luznik, L., Flack, K.A., Walker, J.M., van Benthem, M., 2013, The influence of surface gravity waves on marine current turbine performance, International Journal of Marine Energy, Vols. 3-4 2013, pp 27-40.

Maganga, F., Germain, G., King, J., Pinon, G., Rivoalen, E., 2010, Experimental characterisation of flow effects on marine current turbine behaviour and on its wake properties, IET Renewable Power Generation Vol. 4 pp 498-509.

Maitre, T., Amet, E., Pellone, C., 2013, Modeling of the flow in a Darrieus water turbine: Wall grid refinement analysis and comparison with experiments, Renewable Energy, Vol. 51 2013, pp 497-512.

Malmo O., Reitan A., 1985, Wave-power absorption by an oscillating water column in a channel, Journal of Fluid Mechanics, Vol 158, pp 153-175

Mankins, J. C., 1995, , NASA Office of Space Access and Technology (http://www.hq.nasa.gov/office/codeq/trl/)

Martin H.R., Kimball R.W., Viselli A.M., and Goupee A.J., 2012, Methodology for Wind/Wave Basin Testing of Floating Offshore Wind Turbines, Proceedings, 31st Int. Conf. on Ocean Offshore \& Arctic Engineering, OMAE2012-83627 83645 Rio de Janeiro, Brazil

Mason-Jones, A., O' Doherty, D. M., Morris, C. E., O' Doherty, T., 2013, Influence of a velocity profile and support structure on tidal stream turbine performance, Renewable Energy, Vol. 52, pp 23-30.

McCormick M.E., 1981, Ocean Wave Energy Conversion, New York: Wiley

Meyer N. I., McDonal Arnskov, M., Vad Bennetzen, L. C. E., Burcharth, H. F., Bunger J., Jacobsen, V., Maegaard, P., Vindelok, S., Nielsen, K., Sorensen, J.N., 2002, Bolgekraftprogram: Afsluttend rapport fra Energistyrelesens Radgivende Bolgekraftudval, Technical Report, Bolgekraftudvalgets Sekretariat, Ramboll, Virum, Denmark 
Milne, I. A., Day, A. H., Sharma, R. N., Flay, R. G. J., 2013, Blade Loads on Tidal Turbines in Planar Oscillatory Flow, Ocean Engineering Vol 60, pp 163-174.

Muthanna, C. Visscher, J. H., and Egeberg, T. F., 2013, An Experimental Investigation of Scale Effects on Offshore Wind Turbine Blades, Proc. 32nd Int. Conf. on Ocean, Offshore and Arctic Engineering OMAE2013, Nantes, France

Mycek, A.B., Gaurier, B., Germain, G., Pinon, G., Rivoalen, E., 2013, Numerical and experimental study of the interaction between two marine current turbines, International Journal of Marine Energy, Vol. 1, pp 70-83.

Mycek P., Gaurier P., Germain G., Pinon G., Rivoalen E., 2014, Experimental study of the turbulence intensity effects on marine current energy turbines behaviour, Part 1: single turbine and Part 2: two interacting turbines, Renewable Energy, 2014, Vol. 68 , P. 876-892

Myers, L.E., Bahaj, A.S., 2012, An experimental investigation simulating flow effects in first generation marine current energy converter arrays, Renewable Energy, Vol. 37, pp 28-36.

Neill, S.P., Litt, E.J., Couch, S.J., Davies, A.G., 2009, The impact of tidal stream turbines on large-scale sediment dynamics, Renewable Energy, Vol. 34, pp 2803-2812.

Neill, S.P., Jordan, J.R., Couch, S.J., 2012, Impact of tidal energy converter (TEC) arrays on the dynamics of headland sand banks, Renewable Energy, Vol. 37, pp 387-397.

Nicholls-Lee, R.F., Turnock, S.R., Boyd, S.W., 2013, Application of bend-twist coupled blades for horizontal axis tidal turbines, Renewable Energy, Vol. 50, pp 541-550.

Obhrai, C., Kalvig, S., Gudmestad, O. T., 2012, A Review of Current Guidelines and Research on Wind Modelling for the Design of Offshore Wind Turbines Proceedings Twenty-second International Offshore and Polar Engineering Conference Rhodes, Greece 
Oskamp, J., Ozkan-Haller, H.T., 2012, Power calculations for a passively tuned point absorbed wave energy converter on the Oregon Coast, Renewable Energy, Vol 45, 72-77

Paillard, B., Hauville, F., Astolfi, J.A., 2013, Simulating variable pitch crossflow water turbines: A coupled unsteady ONERA-EDLIN model and streamtube model, Renewable Energy, Vol. 52, pp 209-217.

Parmeggiani, S., Kofoed, J. P. \& Friis-Madsen, E., 2013, Experimental Update of the Overtopping Model Used for the Wave Dragon Wave Energy Converter Energies, Vol. 6, pp 19611992;

Payne G. S., Taylor J. R. M., Bruce T., Parkin P., 2008, Assessment of boundary-element method for modelling a free-floating wave energy device. Part 2: Experimental validation, Ocean Engineering, Vol 35, 342-357

Pinon, G., Mycek, P., Germain, G., Rivoalen, E., 2012, Numerical simulation of the wake of marine current turbines with a particle method, Renewable Energy, Vol. 46, pp 111-126.

Pizer D., 1992, Numerical prediction of the performance of a Solo Duck, Technical report, Edinburgh University

Ponta, F.L., Jacovkis, P.M., 2008, Marine Current Power Generation by Diffuser-augmented Floating Hydro-turbines, Renewable Energy, Vol. 33 2008, pp 665-673.

Popko, W., Vorpahl, F, Zuga, A., Kohlmeier, M., Jonkman, J., Robertson, A., Larsen, T. J., Yde, A., Sætertrø, K., Okstad, K. M., Nichols, J., Nygaard, T. A., Gao, Z., Manolas, D., Kim, K., Yu, Q., Shi, W., Park, H., Vásquez-Rojas, A., Dubois, J., Kaufer, D., Thomassen, P., de Ruiter, M. J., Peeringa, J. M., Zhiwen, H., von Waaden, H., 2012, Offshore Code Comparison Collaboration Continuation (OC4), Phase I - Results of Coupled Simulations of an Offshore Wind Turbine with Jacket Support Structure Proceedings, Twenty-Second International Offshore and Polar Engineering Conference Rhodes, Greece, June 17-22, 2012 
Previsic, M., Bedard, R., Hagerman, G., 2004, EI2 EPRI Assessment: Offshore wave energy conversion devices, Technical Report, E2I EPRI WP-004-US-Rev1, Electricity Innovation Institute, USA.

Renzi E., Dias F., 2012, Resonant behaviour of an oscillating wave energy converter in a channel, Journal of Fluid Mechanics, Vol. 701, pp 482-510

Robertson, A., Jonkman, J., Musial, W., Vorpahl, F. and Popko, W., 2013, Offshore Code Comparison Collaboration, Continuation: Phase II Results of a Floating Semisubmersible Wind System, Proceedings, EWEA Offshore 2013, Frankfurt, Germany

Robertson, A., Jonkman, J., Vorpahl, F., Qvist, J., Yde, A., Popko, W., Froyd, L., Nygaard, T. A., Buils, R., Chen, X., Armendáriz, J. A., Uzunoglu, E., Guedes Soares, C., Luan, C., Yutong, H., Pengcheng, F. Larsen, T., Nichols, J., Lei, L., Manolas, D., Heege, A., Vatne, S., Ormberg, H., Duarte, T. Godreau, C., Hansen, H., Nielsen, A., Riber, H. Le Cunff, C., Beyer, F., Yamaguchi, A. Jung, K. J., Shin, H., Alves, M., Shi, W., Park, H., Guerinel, M., 2014, Offshore Code Comparison Collaboration Continuation within IEA Wind Task 30 : Phase II Results regarding a floating semisubmersible wind system, Proceedings, 33rd International Conference on Ocean, Offshore and Arctic Engineering, OMAE2014, San Francisco, CA, USA

Ruellan, M., BenAhmed, H., Multon, B., Josset, C., Babarit, A., Clément, A., 2010, Design methodology for a SEAREV wave energy converter, IEEE Transactions on Energy Conversion, Vol 25 (3), 760-767

Salter S., 1974, Wave power, Nature, Vol. 249, pp 720-724

Salvatore, F., Greco, L., 2008, Development and Assessment of Performance Prediction Tools for Wind and Tidal Turbines, RINA Conference on Marine Renewable Energy, London, UK, November, 2008.

Saulnier, J. B., Clément, A. H., Falcao, A. F. de O., Pontes, T., Prevosto, M., Ricci, P., 2011, Wave groupiness and spectral bandwidth as relevant parameters for the performance assessment of wave energy converters, Ocean Engineering, Vol. 38 (1), pp 130-147 
Sheng, W., Thiebaut, F., Babuchon, M., Brooks, J., Lewis, A. \& Alcorn, R., 2013, Investigation to Air Compressibility of Oscillating Water Column Wave Energy Converters, Paper OMAE201310151, Proceedings, 32nd Int. Conf. on Ocean, Offshore and Arctic Engineering (OMAE2013) June 9-14, 2013, Nantes, France

Shin H., Kim B., Dam P.T., and Jung K., 2013, Motion of OC4 5MW Semi-submersible Offshore Wind Turbine in irregular waves, Proceedings, 32nd International Conference on Ocean Offshore \& Arctic Eng., OMAE2013-10463 Nantes, France

Siegel S.G., Fagley C., Seidel J., Jeans T., 2013, 3D wave radiation efficiency of a double cycloidal wave energy converter, Proceedings, $10^{\text {th }}$ European Wave and Tidal Energy Conference, Aalborg, Denmark

Signorelli, C., Villegas, C. \& Ringwood, J., 2011, Hardware-In-The-Loop Simulation of a Heaving Wave Energy Converter, Proc. 9th European Wave and Tidal Energy Conference (EWTEC 2011), Southampton UK.

Soulard, T., Babarit, A., 2012, Numerical assessment of the mean power production of a combined wind and wave energy platform, Proceedings, $31^{\text {st }}$ International Conference on Offshore Mechanics and Arctic Engineering, Rio de Janeiro, Brazil

Stratigaki V., Troch, P., Stallard T., Forehand D., Kofoed J. P., Folley M., Benoit M., Babarit A., and Kirkegaard, J. 2014, Wave Basin Experiments with Large Wave Energy Converter Arrays to Study Interactions between the Converters and Effects on Other Users in the Sea and the Coastal Area, Energies 2014, 7(2), 701-734

Tedeschi, E., Carraro, M., Molinas, M., Mattavelli P., 2011, Effect of control strategies and power take-off efficiency on the power capture from sea waves, IEEE Transactions on energy conversion, Vol 26 (4), pp 1088-1098 
Urbina, R., Peterson, M., Kimball, R. W., de Bree, G.S., Cameron, M.P. 2013, Modeling and validation of a cross flow turbine using free vortex model and a modified dynamic stall model, Renewable Energy, Vol. 50 2013, pp 662-669.

van Bussel, G. J. W., 2007, The Science of Making More Torque From Wind: Diffuser Experiments and Theory Revisited, Journal of Physics: Conference Series, Vol. 75 (1), 012010

Vicente, P. C., Falcao, A. F. de O., Gato, L. M. C., Justino, P. A. P., 2009, Dynamics of arrays of floating point absorbed wave energy converters with inter-body and bottom slack-mooring connections, Applied Ocean Research, Vol. 31, pp 267-281

Wang, D., Atlar, M., Sampson, R., 2007, An experimental investigation on cavitation, noise, and slipstream characteristics of ocean stream turbines. Proc. Inst. Mech. Eng. Vol 221, Part A: J Power Energy, pp 219-231.

Weber, J., 2007, Representation of non-linear aero-thermodynamic effects during small scale physical modelling of OWC WECs, Proceedings, 7th European Wave and Tidal Energy Conference (EWTEC 2007)

Whelan, J. I., Graham, J. M. R., Peirò, J., 2009, A free-surface and blockage correction for tidal turbines, J. Fluid Mechanics, 2009, Vol. 624, pp 281-291.

Xiao, Q., Liao, W., Yang, S., \& Peng, Y., 2012, How motion trajectory affects energy extraction performance of a biomimic energy generator with an oscillating foil, Renewable Energy, Vol. 37, No. 1, pp 61-75

Xiao, Q., Liu, W., Incecik, A. 2013, Flow control for VATT by fixed and oscillating flap. Renewable Energy, Vol. 51 2013, pp 141-152.

Yang, B., Lawn, C., 2011, Fluid dynamic performance of a vertical axis turbine for tidal currents, Renewable Energy, Vol. 36, pp 3355-3366. 
Yang, L., Hals, J., Moan, T., 2010, Analysis of dynamic effects relevant for the wear damage in hydraulic machines for wave energy conversion, Ocean Engineering, Vol 337 (13), pp 1089-1102

Yu, Y-H, Li, Y., 2012, RANS Simulation of the heave performance of a two-body floating-point absorbed wave energy system, Computers and Fluids, Vol. 73, pp 104-114

Zamora-Rodriguez, R., Gomez-Alonso, P., Amate-Lopez, J., De-Diego-Martin, V., Dinoi, P. \& Souto-Iglesias, A., 2014, ,Model Scale Analysis of a TLP Floating Offshore Wind Turbine‘, Proceedings, 33rd Int. Conf. on Ocean, Offshore \& Arctic Engineering, (OMAE2014), OMAE2014-24089, June 8-13, 2014, San Francisco, California, USA 
Table 1. Guidelines generated by International Bodies

\begin{tabular}{|c|c|c|c|}
\hline Organisation & $\begin{array}{l}\text { Organisation } \\
\text { Type }\end{array}$ & Title & Status (Reference) \\
\hline $\begin{array}{l}\text { International } \\
\text { Electrotechnical } \\
\text { Commission (IEC) } \\
\text { Technical Committee } \\
\text { TC114 } \\
\text { (Marine Energy) } \\
\text { TS 62600-103 }\end{array}$ & $\begin{array}{l}\text { International } \\
\text { Standard- } \\
\text { setting body }\end{array}$ & $\begin{array}{l}\text { Guidelines for the early } \\
\text { stage development of } \\
\text { wave energy } \\
\text { converters: Best } \\
\text { practices } \\
\text { recommended } \\
\text { procedures for the } \\
\text { testing of pre- } \\
\text { prototype scale devices }\end{array}$ & Under Development \\
\hline $\begin{array}{l}\text { International } \\
\text { Electrotechnical } \\
\text { Commission (IEC) } \\
\text { Technical Committee } \\
\text { TC88 } \\
\text { (Wind Turbines) } \\
\text { PT 61400-3-2 } \\
\end{array}$ & $\begin{array}{l}\text { International } \\
\text { Standard- } \\
\text { setting body }\end{array}$ & $\begin{array}{l}\text { Design requirements } \\
\text { for floating offshore } \\
\text { wind turbines }\end{array}$ & $\begin{array}{l}\text { Revision under development } \\
\text { to include Annex addressing } \\
\text { tank testing of FOWTs }\end{array}$ \\
\hline $\begin{array}{l}\text { International Energy } \\
\text { Agency (IEA) } \\
\text { Ocean Energy Systems }\end{array}$ & $\begin{array}{l}\text { Intergovernm } \\
\text { ental } \\
\text { organization }\end{array}$ & $\begin{array}{l}\text { Guidelines for the } \\
\text { Development \& } \text { Testing } \\
\text { of Wave } \text { Energy } \\
\text { Systems }\end{array}$ & $\begin{array}{l}\text { Published } 2011 \\
\text { http://www.ocean-energy- } \\
\text { systems.org/ } \\
\text { oes_reports/annex_ii_reports } \\
\text { / }\end{array}$ \\
\hline
\end{tabular}

Table 2. Guidelines generated by Research Institutes and Projects

\begin{tabular}{|l|l|l|l|}
\hline Organisation & $\begin{array}{l}\text { Organisation } \\
\text { Type }\end{array}$ & Title & Status (Reference) \\
\hline $\begin{array}{l}\text { European Marine } \\
\text { Energy Centre (EMEC) }\end{array}$ & $\begin{array}{l}\text { Open-Sea test } \\
\text { centre (full- } \\
\text { scale \& } \\
\text { nursery) }\end{array}$ & $\begin{array}{l}\text { Tank Testing of Wave } \\
\text { Energy Conversion } \\
\text { Systems }\end{array}$ & $\begin{array}{l}\text { Published 2009 } \\
\text { http://www.emec.org.uk/tan } \\
\text { k-testing-of-wave-energy- } \\
\text { conversion-systems/ }\end{array}$ \\
\hline Equimar & $\begin{array}{l}\text { EU-funded } \\
\text { Research } \\
\text { Project }\end{array}$ & $\begin{array}{l}\text { Best practice for tank } \\
\text { testing of small marine } \\
\text { energy devices }\end{array}$ & $\begin{array}{l}\text { Published 2010 } \\
\text { http://www.equimar.org/equ } \\
\text { imar-project- } \\
\text { deliverables.html }\end{array}$ \\
\hline Marinet & $\begin{array}{l}\text { EU-funded } \\
\text { Research } \\
\text { Project }\end{array}$ & $\begin{array}{l}\text { Ongoing development } \\
\text { of guidelines for wave } \\
\text { and current energy } \\
\text { testing }\end{array}$ & \begin{tabular}{l} 
Under development \\
\hline Supergen Marine
\end{tabular} \\
$\begin{array}{l}\text { UK research } \\
\text { project }\end{array}$ & $\begin{array}{l}\text { Guidance for the } \\
\text { experimental tank } \\
\text { testing of wave energy } \\
\text { converters }\end{array}$ & $\begin{array}{l}\text { Published 2008 } \\
\text { http://www.supergen- } \\
\text { marine.org.uk/drupal/files/re } \\
\text { ports/WEC_tank_testing.pdf }\end{array}$ \\
\hline
\end{tabular}


Table 3 COMPARATIVE ANALYSIS OF NUMERICAL MODELLING TECHIQUES FOR WEC ARRAYS

\begin{tabular}{|c|c|c|c|c|c|c|c|c|c|}
\hline & \multicolumn{4}{|c|}{ Potential flow models } & \multicolumn{4}{|c|}{ Spectral wave models } & \multirow[b]{2}{*}{ CFD } \\
\hline & Linear BIEM & $\begin{array}{c}\text { Semi-analytical } \\
\text { techniques }\end{array}$ & $\begin{array}{c}\text { Time-domain } \\
\text { formulation }\end{array}$ & Nonlinear BIEM & Boussinesq & Mild-slope & Supra-grid & Sub-grid & \\
\hline \multicolumn{10}{|l|}{ Fundamental } \\
\hline $\begin{array}{l}\text { Definition of } \\
\text { hydrodynamics }\end{array}$ & \multicolumn{4}{|c|}{$\begin{array}{l}\text { Implicit body surfaces } \\
\text { Explicit coefficients }\end{array}$} & \multicolumn{2}{|c|}{ Explicit absorption layers } & $\begin{array}{c}\text { Explicit } \\
\text { absorption layer } \\
\end{array}$ & $\begin{array}{l}\text { Explicit source } \\
\text { strength }\end{array}$ & $\begin{array}{l}\text { Implicit fluid } \\
\text { flow } \\
\end{array}$ \\
\hline Nonlinear wave dynamics & \multicolumn{3}{|c|}{ Not capable } & $\begin{array}{c}\text { Implicitly } \\
\text { capable }\end{array}$ & $\begin{array}{c}\text { Implicitly } \\
\text { capable }\end{array}$ & Not capable & \multicolumn{2}{|c|}{$\begin{array}{c}\text { Implicitly capable for phase- } \\
\text { averaged dynamics }\end{array}$} & $\begin{array}{c}\text { Implicitly } \\
\text { capable }\end{array}$ \\
\hline Nonlinear dynamics & \multicolumn{2}{|c|}{ Not capable } & \multicolumn{2}{|c|}{ Implicit solver } & \multicolumn{2}{|c|}{ Explicit absorption layers } & $\begin{array}{c}\text { Explicit } \\
\text { absorption layer }\end{array}$ & $\begin{array}{l}\text { Explicit source } \\
\text { strength }\end{array}$ & Implicit solver \\
\hline Vortex shedding & \multicolumn{2}{|c|}{ Explicit inclusion by linearisation } & \multicolumn{2}{|c|}{ Explicit inclusion } & \multicolumn{2}{|c|}{ Explicit inclusion } & \multicolumn{2}{|c|}{ Explicit inclusion } & Implicit inclusion \\
\hline WEC radiation & \multicolumn{4}{|c|}{ Implicitly capable } & \multicolumn{2}{|c|}{ Explicitly capable } & Not capable & $\begin{array}{c}\text { Explicitly } \\
\text { capable }\end{array}$ & $\begin{array}{l}\text { Implicitly } \\
\text { capable }\end{array}$ \\
\hline Diffraction & \multicolumn{4}{|c|}{ Implicitly capable } & \multicolumn{2}{|c|}{ Explicitly capable } & \multicolumn{2}{|c|}{$\begin{array}{l}\text { Approximated by phase-decoupled } \\
\text { refraction-diffraction }\end{array}$} & $\begin{array}{l}\text { Implicitly } \\
\text { capable }\end{array}$ \\
\hline $\begin{array}{l}\text { Variable bathymetry and } \\
\text { marine currents }\end{array}$ & \multicolumn{4}{|c|}{ Not capable } & $\begin{array}{l}\text { Implicitly } \\
\text { capable }\end{array}$ & $\begin{array}{l}\text { Implicitly } \\
\text { capable }\end{array}$ & \multicolumn{2}{|c|}{ Implicitly capable } & $\begin{array}{l}\text { Implicitly } \\
\text { capable }\end{array}$ \\
\hline \multicolumn{10}{|l|}{ Computational } \\
\hline Primary dependent & Number of panels & $\begin{array}{l}\text { Complexity of } \\
\text { function }\end{array}$ & $\begin{array}{c}\text { Number of panels } \\
\text { and complexity } \\
\text { of equations }\end{array}$ & Number of panels & \multicolumn{2}{|c|}{ Number of cells } & \multicolumn{2}{|c|}{ Number of cells } & Number of cells \\
\hline Determinate of array size & \multicolumn{4}{|c|}{ Quadratic increase with number of WECs } & \multicolumn{2}{|c|}{ Linear increase with spatial area } & \multicolumn{2}{|c|}{ Linear increase with spatial area } & $\begin{array}{l}\text { Linear inc. with } \\
\text { spatial volume }\end{array}$ \\
\hline Solver & Simple a & ad stable & $\begin{array}{l}\text { Simple and poss. } \\
\text { unstable }\end{array}$ & $\begin{array}{c}\text { Complex and } \\
\text { stable }\end{array}$ & $\begin{array}{l}\text { Simple and poss. } \\
\text { unstable }\end{array}$ & Simple and stable & Simple & ad stable & $\begin{array}{l}\text { Complex and } \\
\text { poss. unstable }\end{array}$ \\
\hline Usability & & & & & & & & & \\
\hline Required skill & Low & High & Medium & High & Medium & Low & Low & Medium & High \\
\hline $\begin{array}{l}\text { Software availability in } \\
2012\end{array}$ & $\begin{array}{c}\text { Commercial code } \\
\text { available }\end{array}$ & $\begin{array}{l}\text { Research code } \\
\text { only }\end{array}$ & \begin{tabular}{|c|} 
Commercial code \\
available
\end{tabular} & $\begin{array}{c}\text { Research code } \\
\text { only }\end{array}$ & $\begin{array}{r}\text { Commercial cod } \\
\text { model }\end{array}$ & $\begin{array}{l}\text { e available, WEC } \\
\text { equired }\end{array}$ & $\begin{array}{r}\text { Open-source coc } \\
\text { model }\end{array}$ & available, WEC & \begin{tabular}{|c|}
$\begin{array}{c}\text { Commercial and } \\
\text { open-source code } \\
\text { available }\end{array}$ \\
\end{tabular} \\
\hline Suitability $(* * * *$ - highly & suitable, $* * *$ - mod & erately suitable, * & * - poorly suitable, & * - not suitable ) & & & & & \\
\hline Localised effects & $* * *$ & $*$ to $* * *$ & *** & $* * *$ & $* *$ & $* *$ & * & * & $* * * *$ \\
\hline Dynamic control & $*$ & $*$ & $* * * *$ & $* * * *$ & $*$ & $*$ & $*$ & $*$ & *** \\
\hline AEP (small WEC array) & $* * *$ & $* * *$ & ** & $* *$ & $* * *$ & $* * *$ & ** & $* * *$ & $* *$ \\
\hline AEP (large WEC array) & $* *$ & $* * *$ & $* *$ & $* *$ & $* * *$ & $* * *$ & $* *$ & $* * *$ & $* *$ \\
\hline Environmental impact & $*$ & $*$ & * & $*$ & $* * *$ & $* * *$ & $* * * *$ & $* * * *$ & $* *$ \\
\hline
\end{tabular}


Table 4 Offshore Wind Modelling Tools (Robertson, et al., 2014)

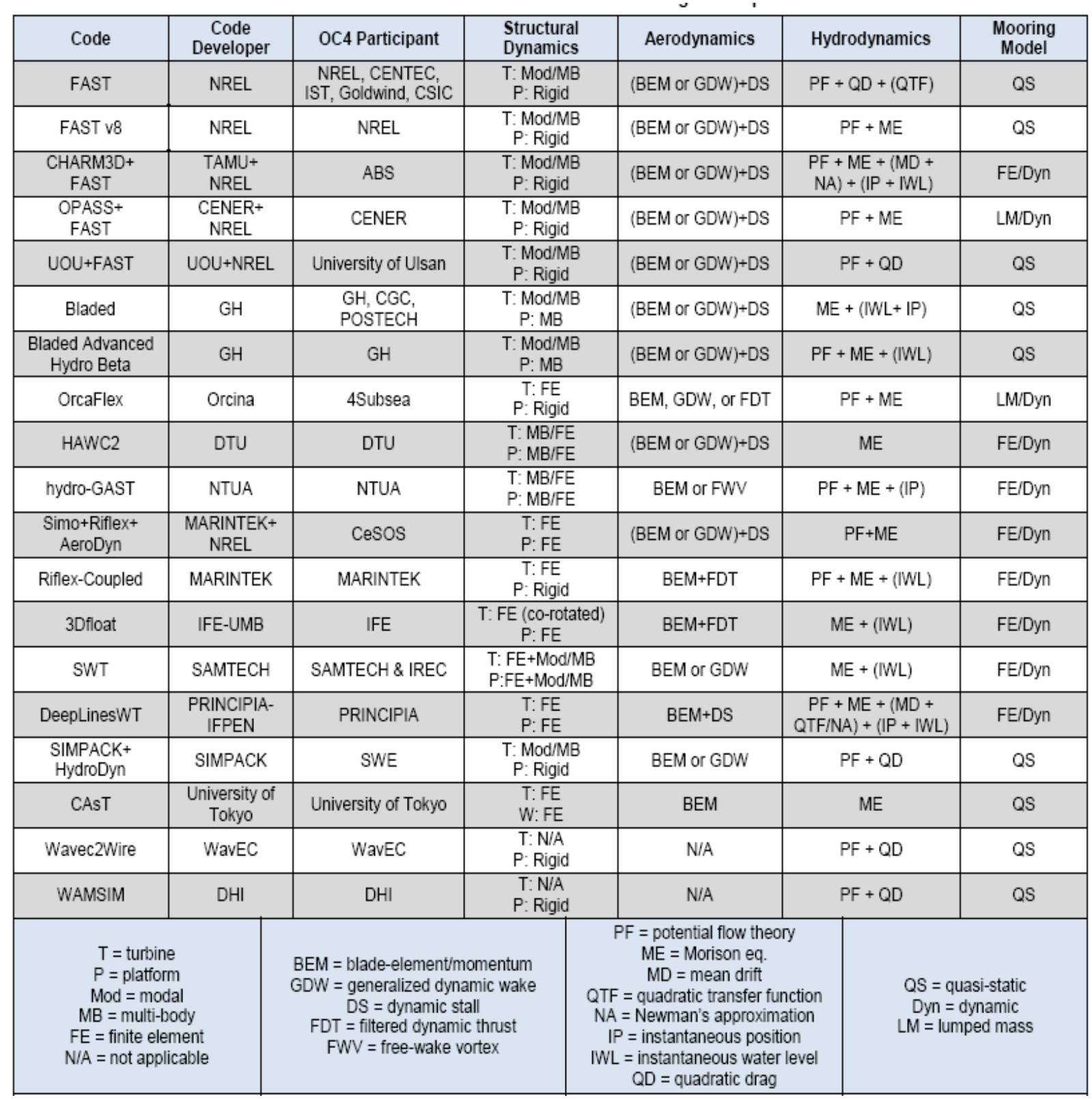




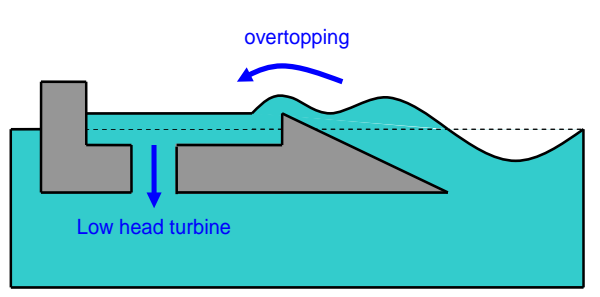

(a)

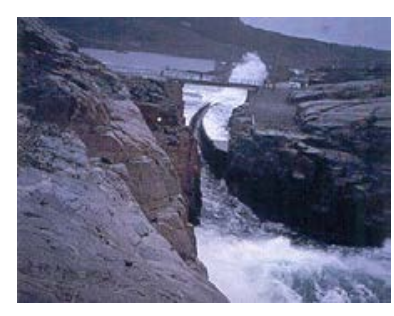

(b)

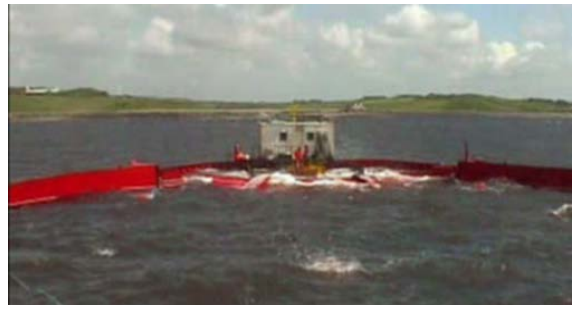

(c)

Figure 1. Overtopping Devices: (a) Schematic Diagram; (b) TAPCHAN built onshore in Norway in the 1980s; (c) 1/4.5 scale model of floating device Wavedragon deployed in Denmark in 2003.

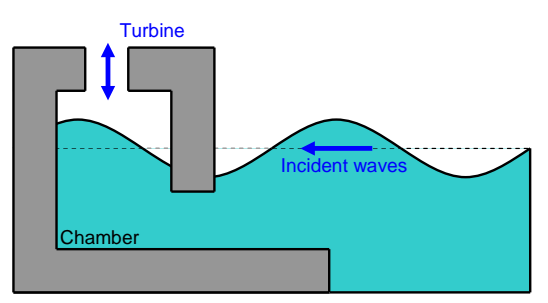

(a)

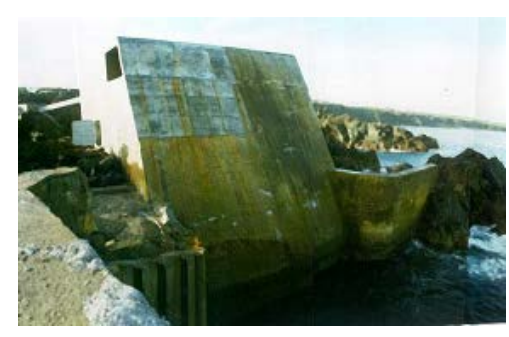

(b)

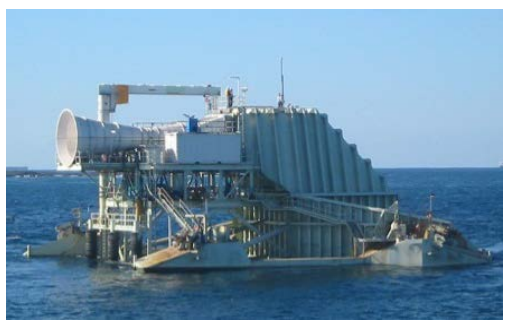

(c)

Figure 2. Oscillating Water Column Devices: (a) Schematic; (b) Pico shore-based OWC built in the Azores in 1999; (c) Oceanlinx floating OWC deployed in 2010 in New South Wales Australia 


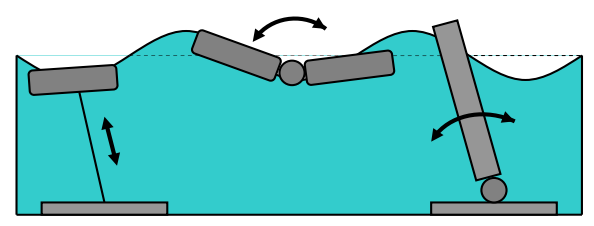

(a)

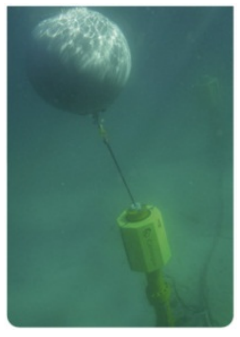

(b)

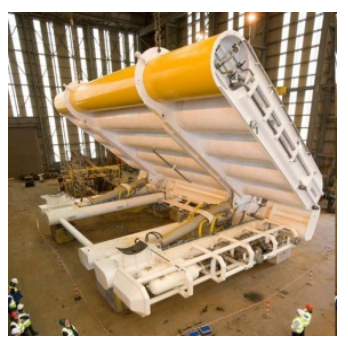

(c)

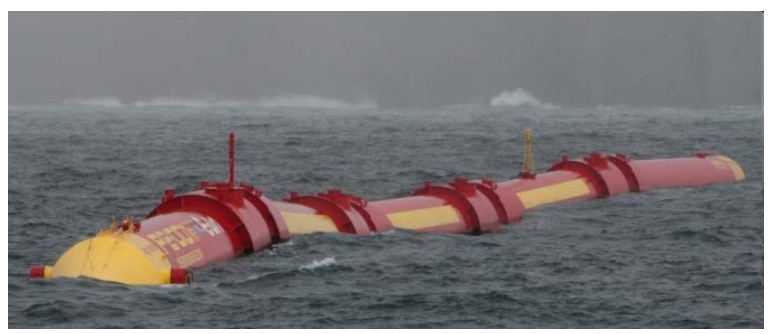

(d)

Figure 3. Oscillating Body Devices: (a) Schematic; (b) Carnegie's Ceto heaving buoy; (c) Aquamarine's Oyster device; (d) Pelamis Wave Power's P2 device. Devices c) and d) have been tested at the European Marine Energy Centre (EMEC) full-scale test site in the UK. 

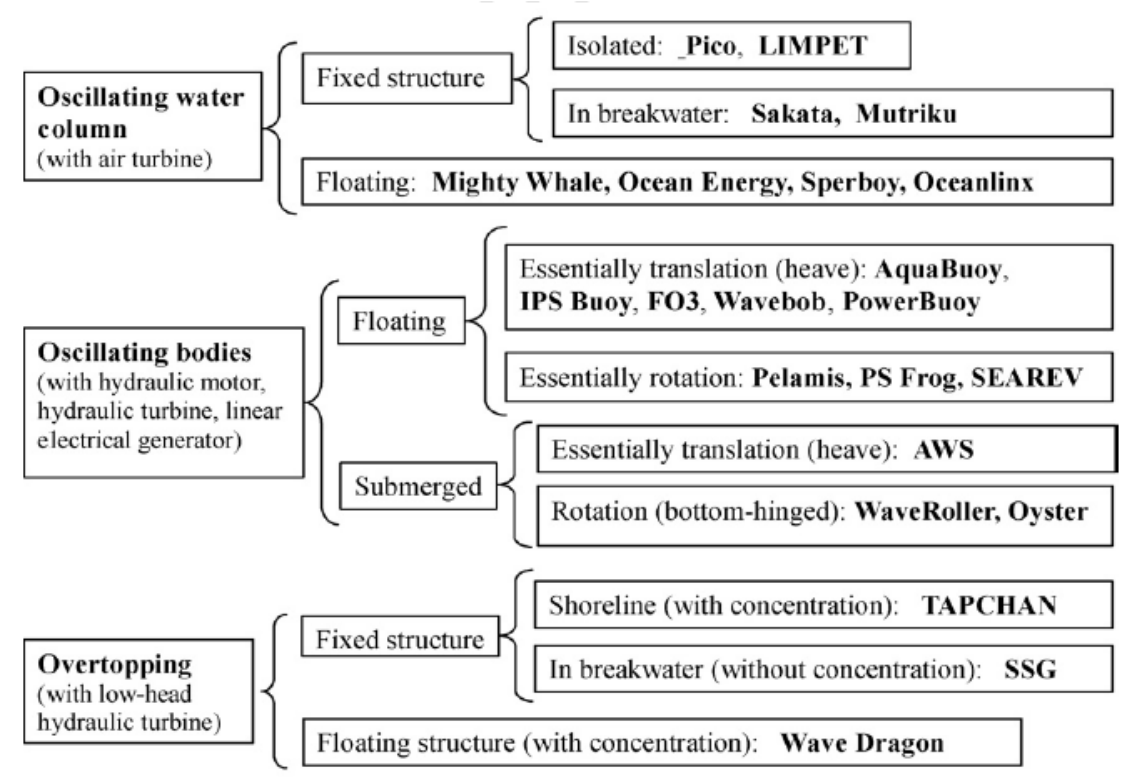

Figure 4. Classification of wave energy technologies (from Falcao (2009)) 


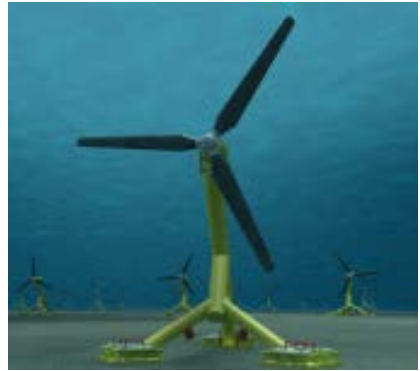

(a)

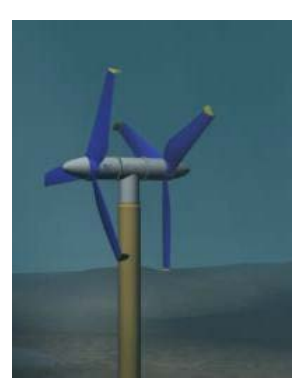

(d)

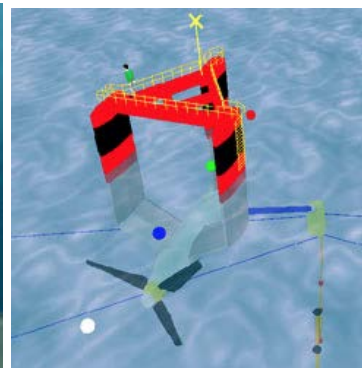

(b)

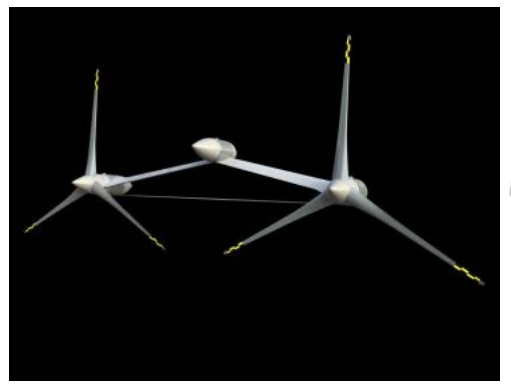

(e)

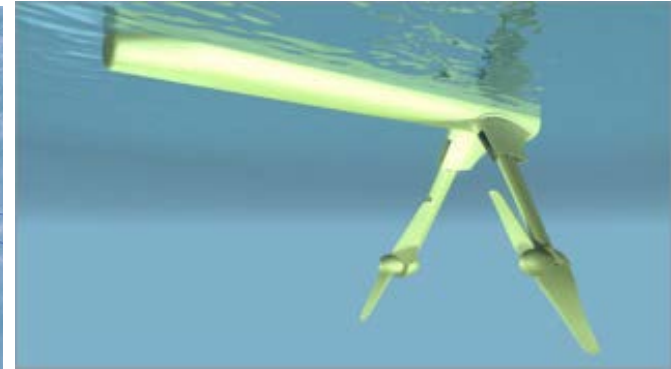

(c)

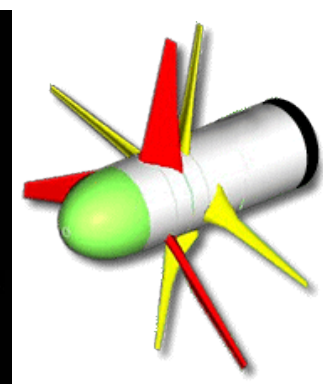

(f)

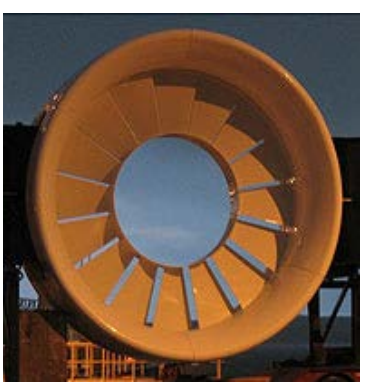

(g)

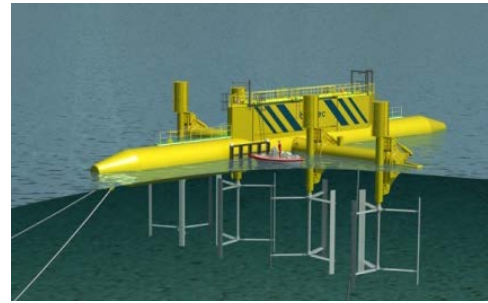

(h)

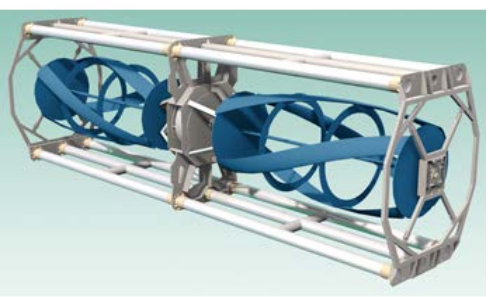

(i)

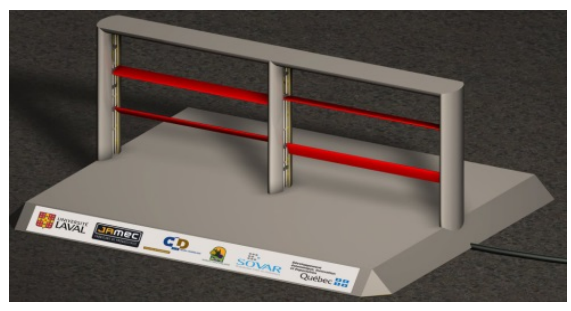

(j)

Figure 5 Examples of current energy devices: a) three-bladed bottom-fixed turbine b) floating single turbine device, c) floating dual turbine device, d) dual turbine bottom-fixed device, e) dual turbine mid-water device f) contra-rotating mid-water device g) ducted turbine (h) Vertical-axis Darrieus turbine cluster (i) Gorlov turbine (j) Oscillating foil device 


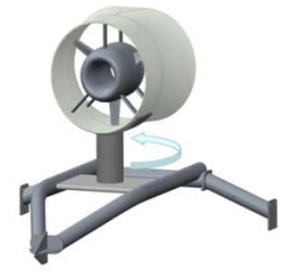

(a)

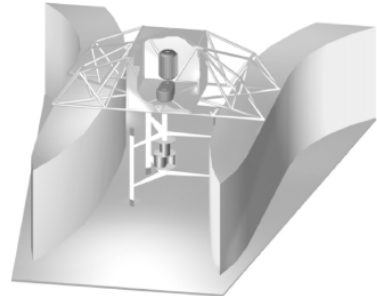

(b)

Figure 6 Diffusers: (a) HACT: Luquet et al. 2013); (b) VACT: (Ponta et al., 2008).
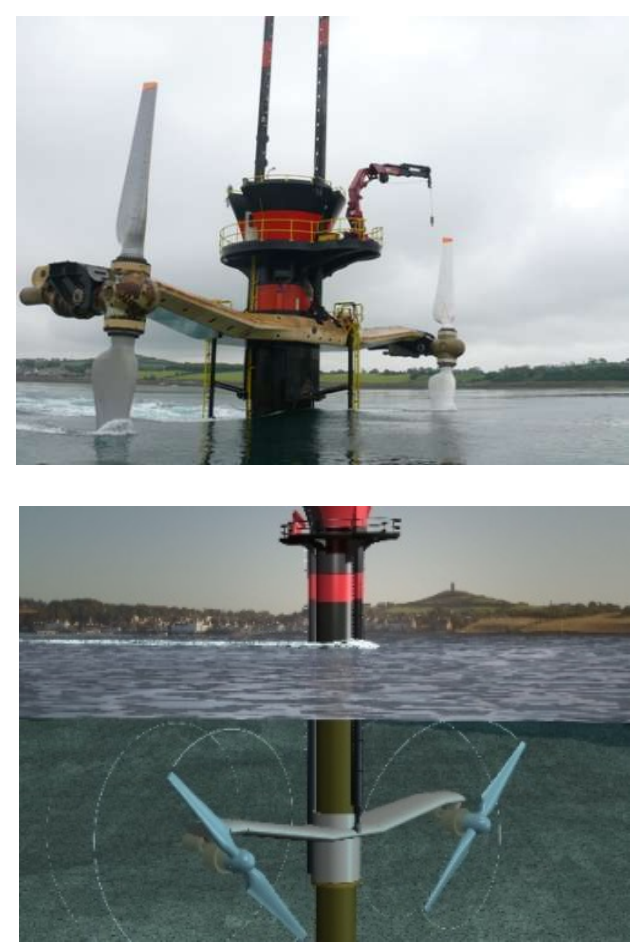

Figure 7. The Seagen 1.2 MW device operating at Strangford Lough, Northern Ireland (U.K). 


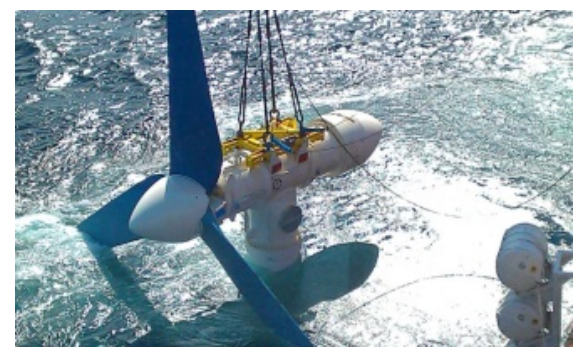

(a)

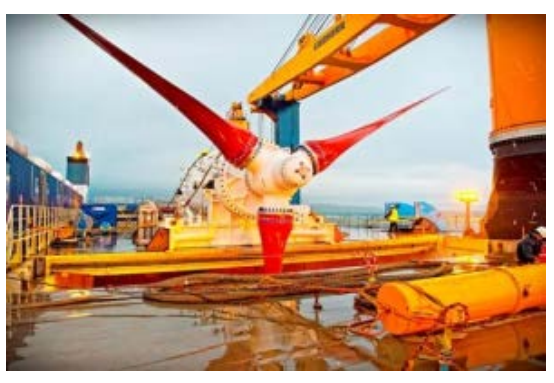

(b)

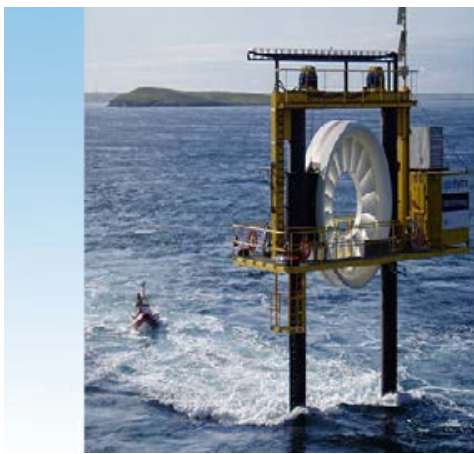

(c)

Figure 8 Examples of horizontal turbine prototypes under assessment in field tests: (a) Voith Hydro Test Turbine, Jindo, Korea; (b) Andritz Hydro Hammerfest HS1000, EMEC, Scotland; (c) Open Hydro Test Turbine, EMEC Scotland 


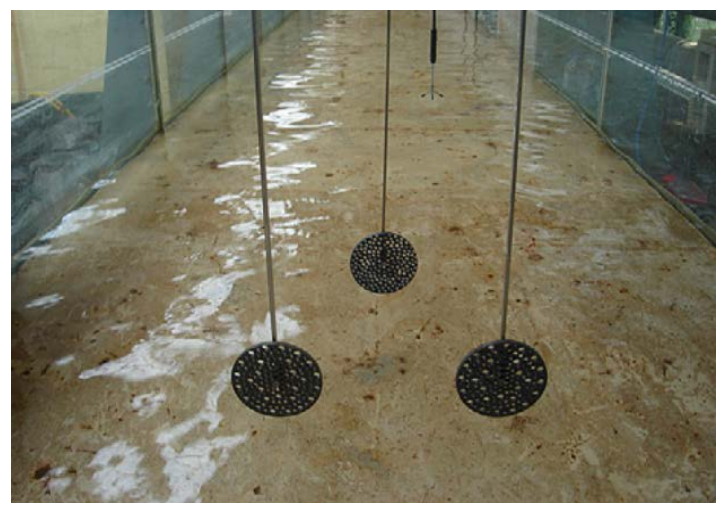

Figure 9 Actuator disks used to simulate turbine arrays in flume tank tests

(Myers and Bahaj, 2011) 


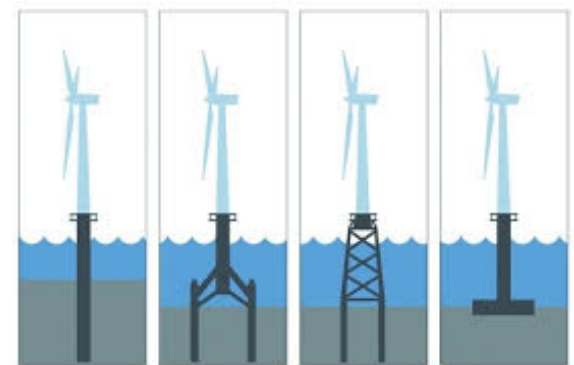

(a)

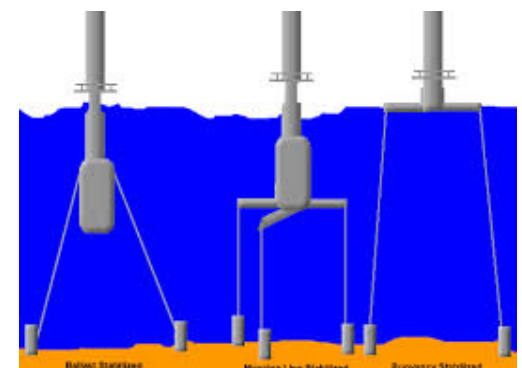

(b)

Figure 10 Offshore wind turbine foundation types:

(a) Bottom Mounted Wind Turbines : monopile, tripod, jacket, gravity base;

(b) Floating Offshore Wind Turbines: Ballast-stabilised, mooring-stabilised, buoyancy-stabilised

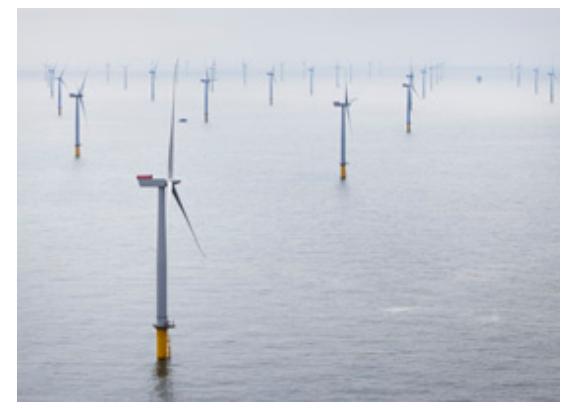

Figure 11 The largest offshore wind farm London Array (UK). 


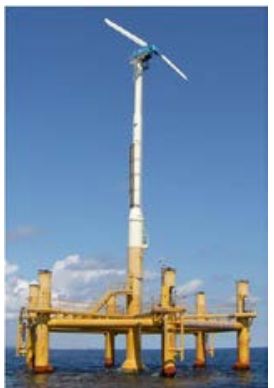

(a)

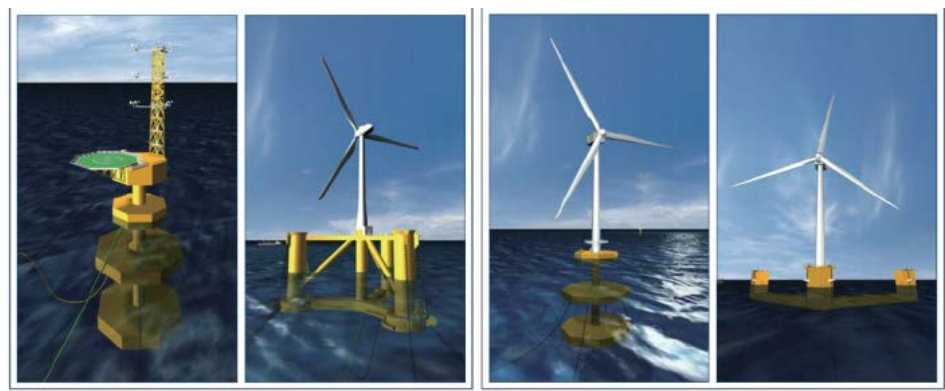

(e)

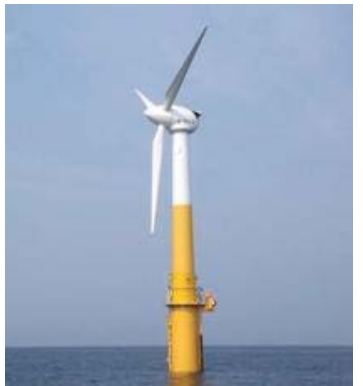

(c)

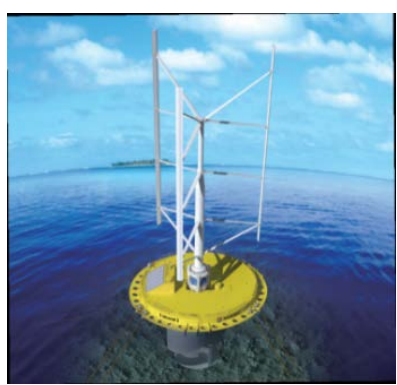

(f)

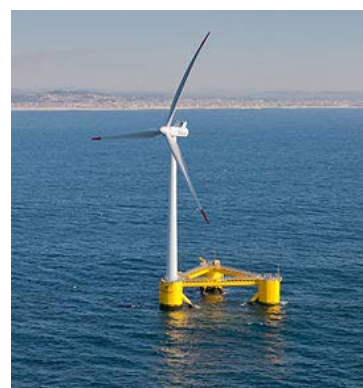

(d)

Figure 12 Prototypes of floating offshore wind turbines (FOWTs):

(a) Blue H TLP (Netherlands); (b) Hywind SPAR (Norway); (c) GOTO Spar (Japan). (d) Wind Float Semi-sub (Portugal); (g) Fukushima Project (Japan); (h) SKWID Hybrid Vertical axis wind turbine / current turbine (Japan) 


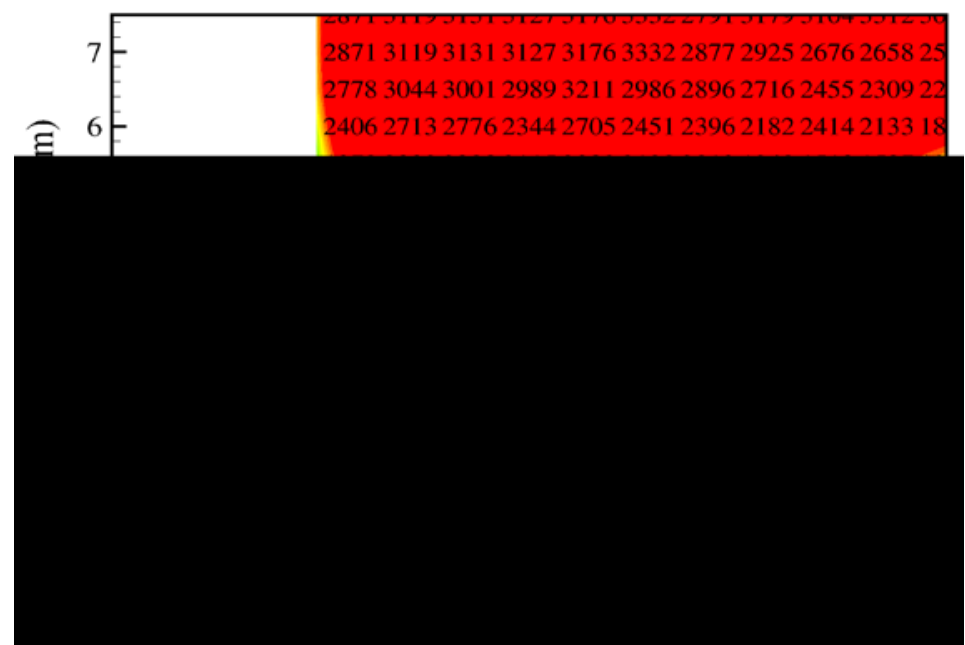

Figure 13: Power matrix of a bottom hinged oscillating surge wave converter. (Babarit et al., 2012) 


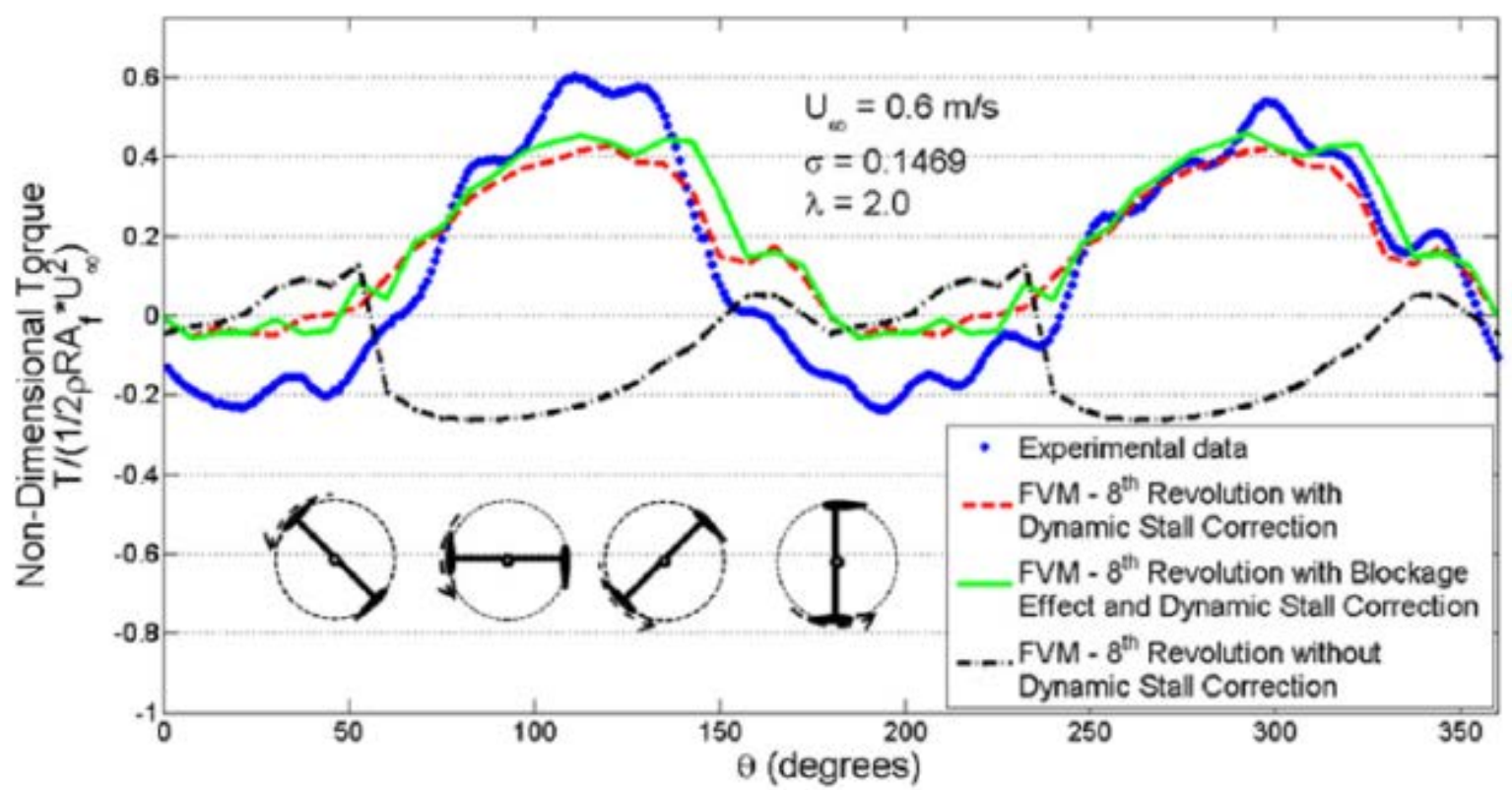

Figure 14. Modelling Dynamic Stall effect on blade loads (Urbina et al., 2013) 


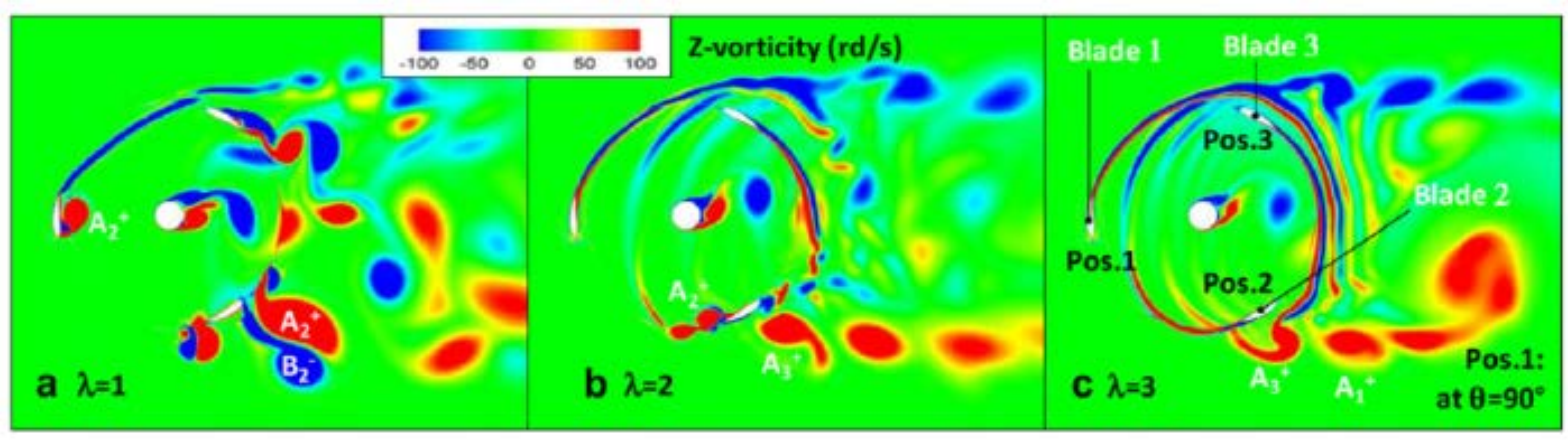

Fig. 18. Vortices structures (2D flow), for $\lambda=1,2 \& 3$.

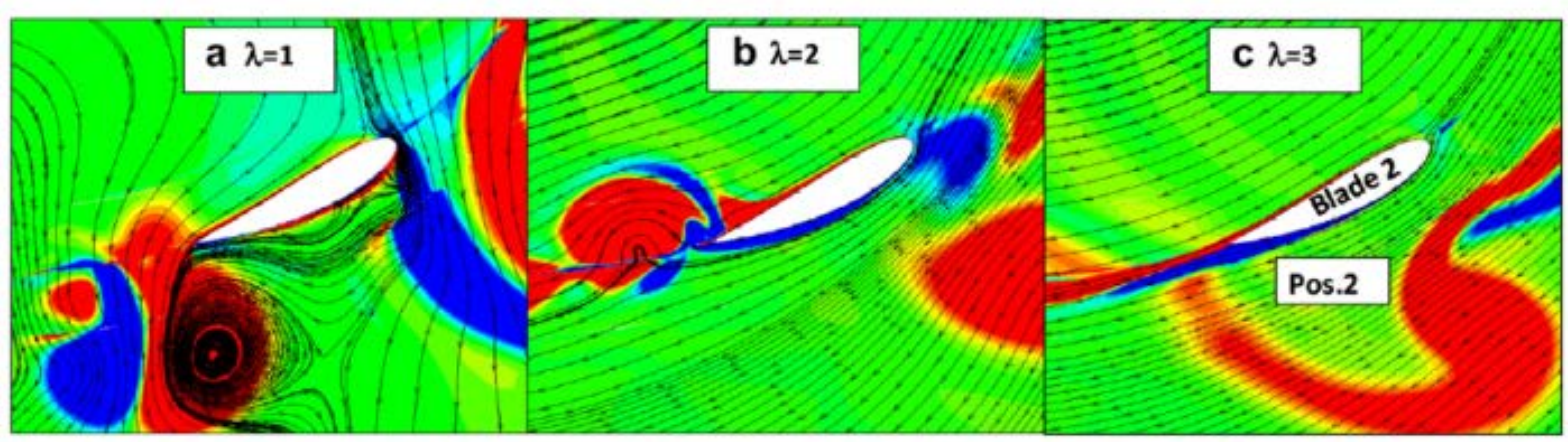

Figure 15. Vorticity field and streamlines calculated across a VACT (Maitre et al., 2013) 

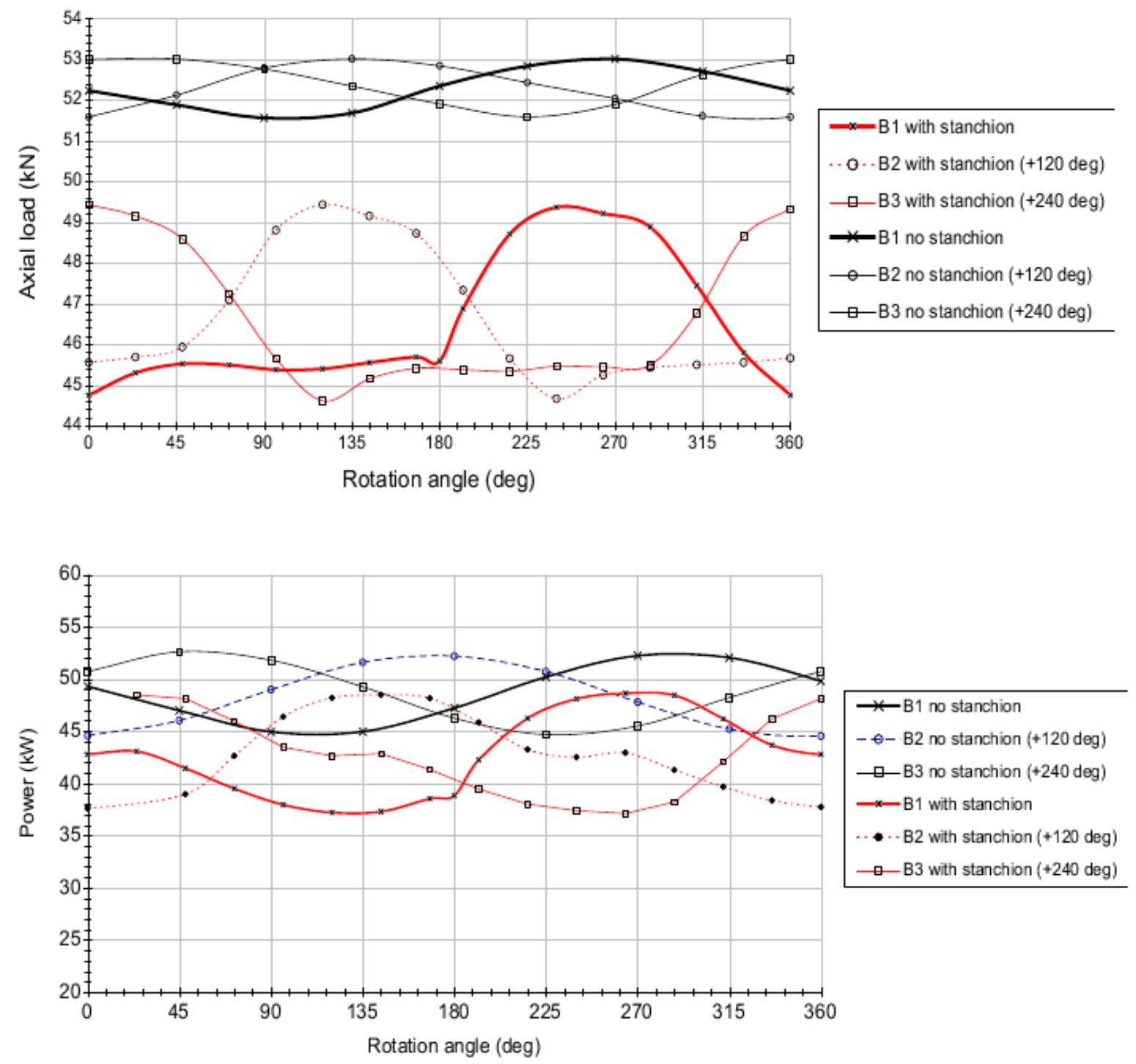

Figure 16. Transient axial force (top) and power (bottom) on isolated axial rotor and upstream of a stanchion (Maison-Jones et al., 2013) 


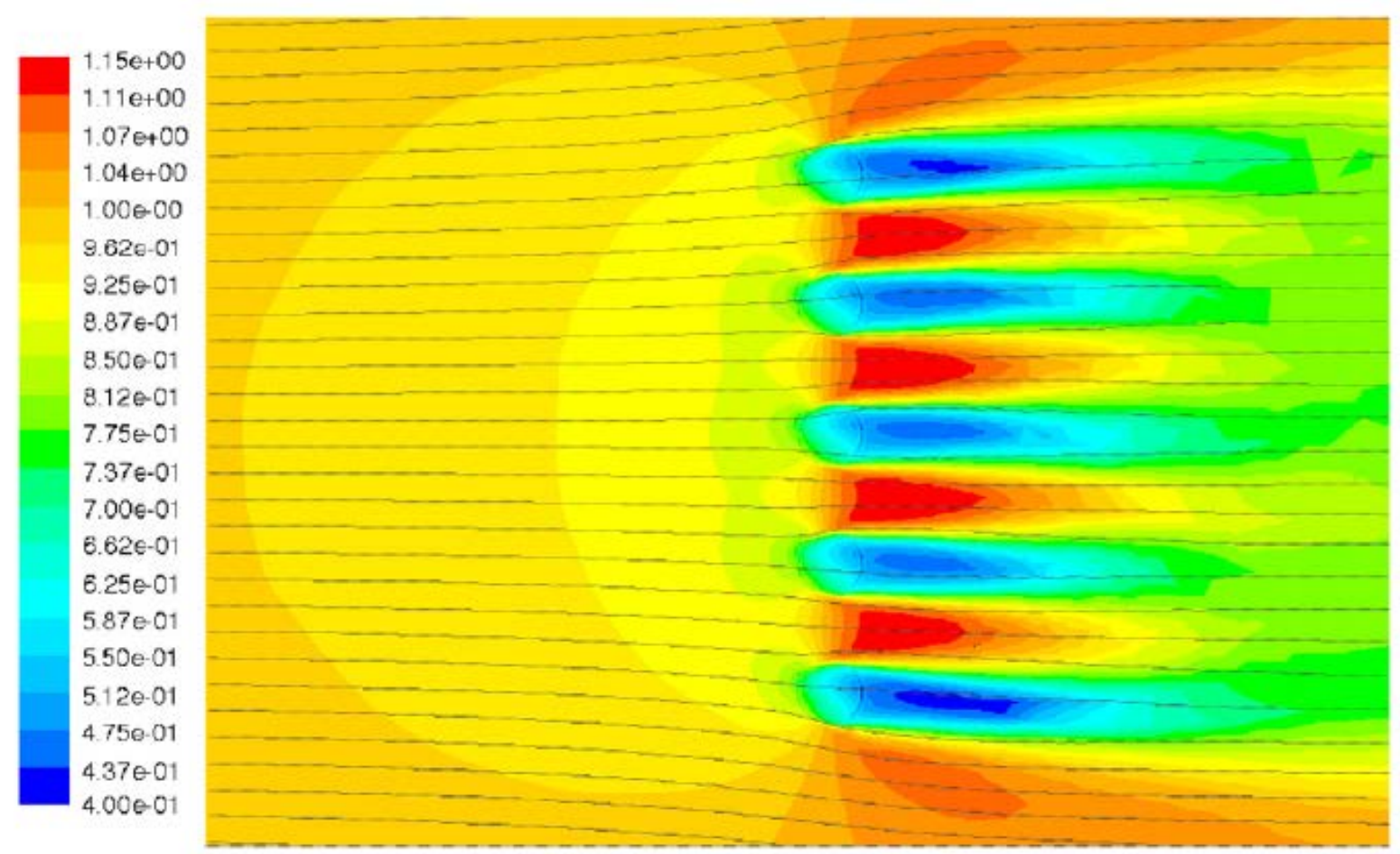

Figure 17. Axial velocity prediction across a 5-unit turbine row

(from Antheaumea et al., 2008) 
Target blade weight for 1:80 scaled model test : $35 \mathrm{~g}$

1. To match small blade target weight, Compressed Styrofoam + Paint Coating - Weight: Around 110g

- Too small strength $\rightarrow$ Additional weight reduction is impossible

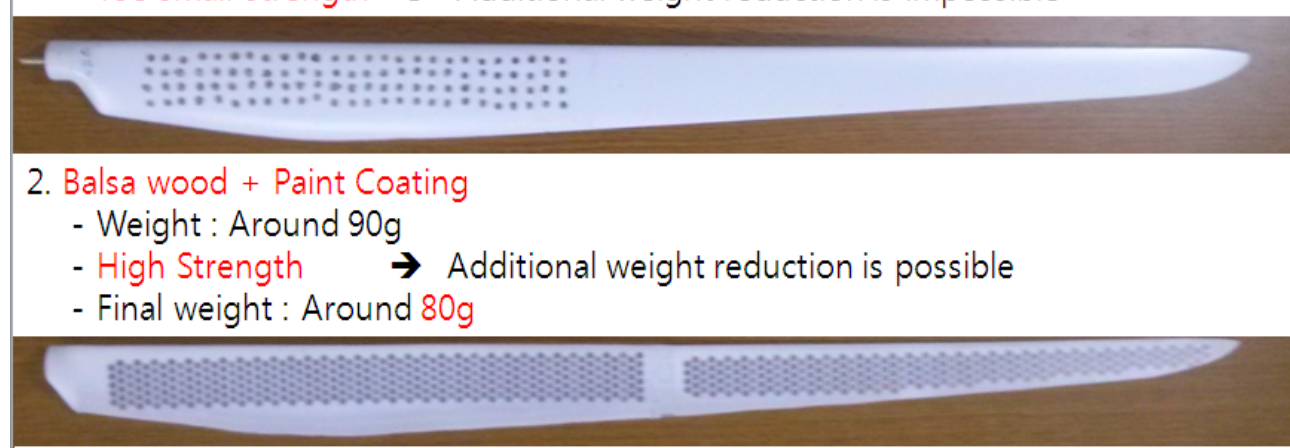

3. DuraForm PA Plastic only

- Weight: Around 40g

- To use a 3D printer $\rightarrow$ Predictive modelling is possible

$\rightarrow$ Making Small weight blade with high accurately

- Material limitation

Figure 18 1:80 scale model rotor blades for a 5MW wind turbine produced by the University of Ulsan, Korea using a 3D printer 